\title{
Structural and Morphological Conversion between Two Co-Based MOFs for Enhanced Water Oxidation
}

Li Zhong, ${ }^{a}$ Junyang Ding, ${ }^{a}$ Xian Wang, ${ }^{a}$ Lulu Chai, ${ }^{a}$ Ting-Ting Li, ${ }^{b}$ Kongzhao Su, ${ }^{\mathrm{c}}$ Yue Hu, ${ }^{*}$ a Jinjie Qian, ${ }^{*}$ a and Shaoming Huang, ${ }^{*}$,

${ }^{a}$ College of Chemistry and Materials Engineering, Wenzhou University, Wenzhou, 325000, China

${ }^{\mathrm{b}}$ Chemistry Institute for Ssynthesis and Green Application, School of Materials Science and Chemical Engineering, Ningbo University, 818 Fenghua Road, Ningbo, 315211, PR China

'State Key Laboratory of Structural Chemistry, Fujian Institute of Research on the Structure of Matter, Chinese Academy of Sciences, Fuzhou, 350002, China

${ }^{\mathrm{d} S c h o o l ~ o f ~ M a t e r i a l s ~ a n d ~ E n e r g y, ~ G u a n g d o n g ~ U n i v e r s i t y ~ o f ~ T e c h n o l o g y, ~ G u a n g z h o u, ~ G u a n g d o n g, ~}$ 510006, China. 


\section{Table of Content}

1. Crystal structure information......................................................................... 10

2. Additional structure discussion of coordinationenvironment in mutual crystal

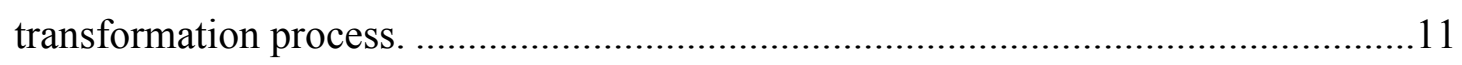

2.1 Connectedand cleavaged nodes............................................................ 11

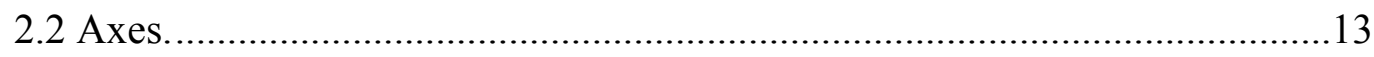

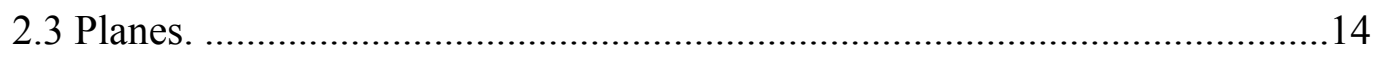

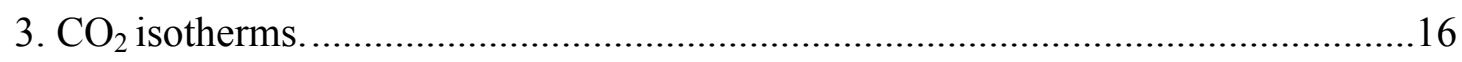

4. Additional structure transformation during OER process.....................................17

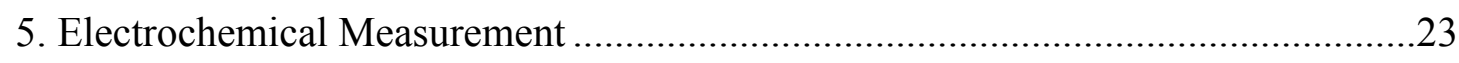

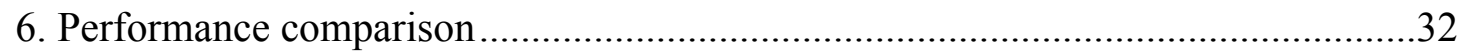

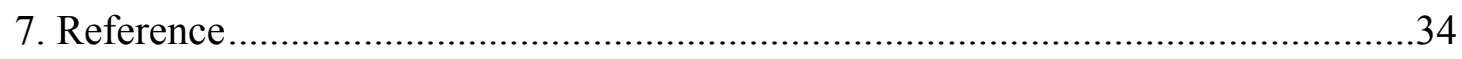


1. Crystal structure information.

\begin{tabular}{|c|c|c|c|}
\hline Lable & Co1 & O3 & O1 \\
\hline Origin & & Formate & BPTC- \\
\hline Occupancy rate & 0.5 & 1 & 0.5 \\
\hline Electric charge & $(+3)^{*} 0.5$ & $(-1)^{*} 1$ & $(-1)^{*} 0.5$ \\
\hline Electric charge & +3 & -1 & -1 \\
\hline /per atom & & & \\
\hline
\end{tabular}

Table S1. Atom valence state of BMM-11. 

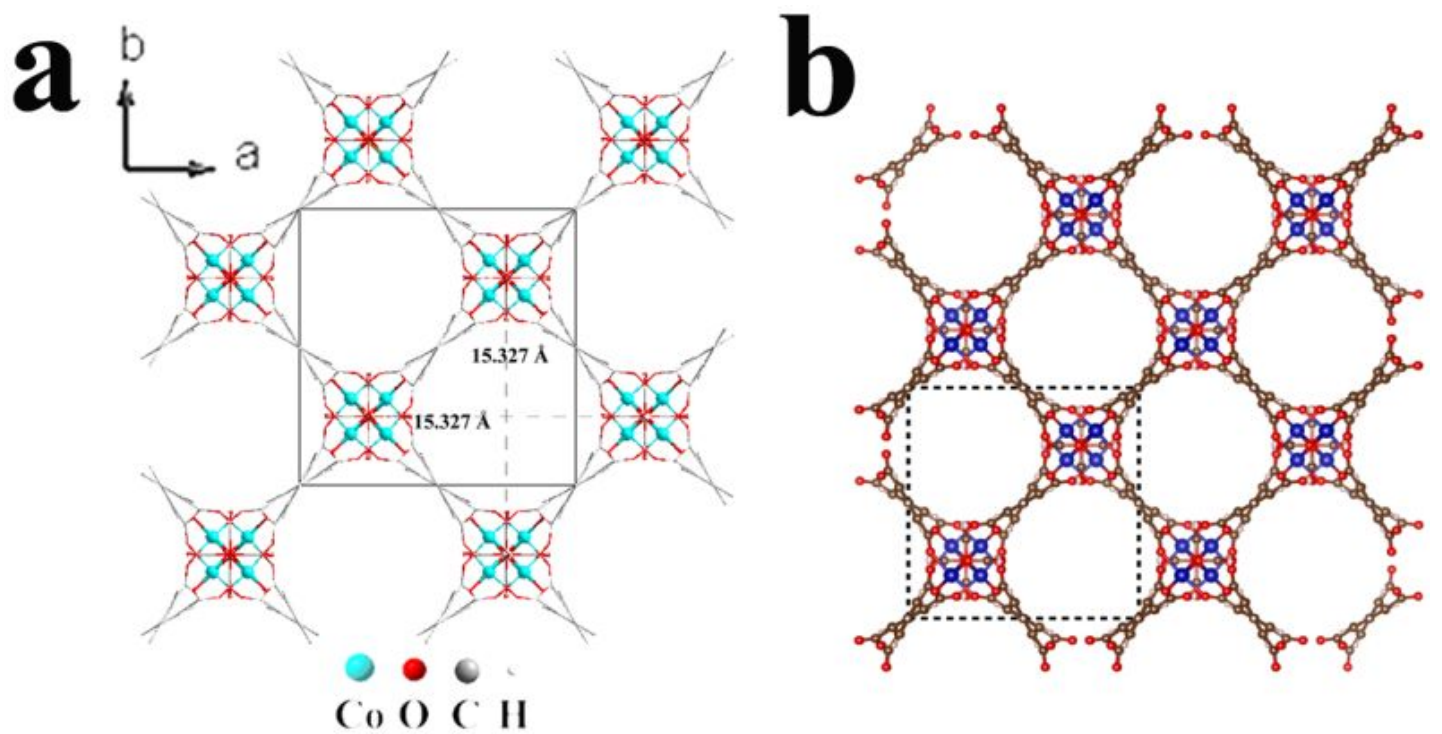

Figure S1. a-b) 1D channels exist with a diameter of $15.327 \AA \times 15.327 \AA$ along $c$ axis. 


\begin{tabular}{|c|c|c|}
\hline Items & BMM-11 & BMM-12 \\
\hline CCDC & 1912147 & 1912148 \\
formula & $\left(\mathrm{C}_{18} \mathrm{H}_{8} \mathrm{Co}_{2} \mathrm{O}_{12}\right) \mathrm{n}$ & $\left(\mathrm{C}_{40} \mathrm{H}_{36} \mathrm{Co}_{4} \mathrm{~N}_{4} \mathrm{O}_{22}\right) \mathrm{n}$ \\
Mass & $\mathrm{C}_{8} \mathrm{H}_{3} \mathrm{Co} \mathrm{NO}_{7}$ & $\mathrm{C}_{40} \mathrm{H}_{32} \mathrm{~N}_{4} \mathrm{O}_{22} \mathrm{Co}_{4}$ \\
crystal system & Tetragonal & Orthorhombic \\
space group & $I 4_{1} 22$ & $F d d 2$ \\
$a(\AA)$ & $15.327(3)$ & $25.790(4)$ \\
$b(\AA)$ & $15.327(3)$ & $28.045(4)$ \\
$c(\AA)$ & $12.270(3)$ & $36.909(5)$ \\
$\alpha\left(^{\circ}\right)$ & 90.00 & 90.00 \\
$\beta\left(^{\circ}\right)$ & 90.00 & 90.00 \\
$\gamma\left({ }^{\circ}\right)$ & 90.00 & 90.00 \\
$V\left(\AA^{3}\right)$ & $2882.6(13)$ & $26696(7)$ \\
$T(\mathrm{~K})$ & 296 & 173 \\
$Z$ & 8 & 16 \\
$\mathrm{~F}(000)$ & 1128.0 & 9344.0 \\
$\mathrm{GOF}$ & 1.158 & 1.062 \\
$\mathrm{R}_{1}(\mathrm{I}>2 \sigma(\mathrm{I}))$ & $0.0310(1749)$ & $0.0311(15225)$ \\
$\mathrm{wR}_{2}(\mathrm{all} \mathrm{reflections)}$ & $0.0866(1811)$ & $0.0871(16716)$ \\
\hline
\end{tabular}

Table S2. Summary of Crystal Data and Refinement Results for BMM-11, BMM-12. 


\section{a $A U$ of $B M M-12$}

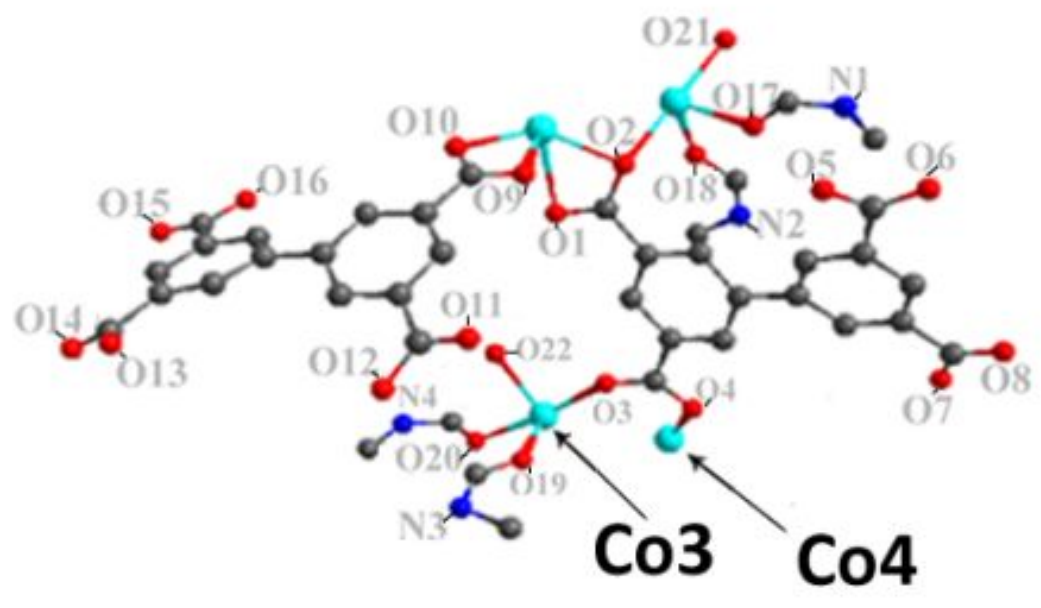

b
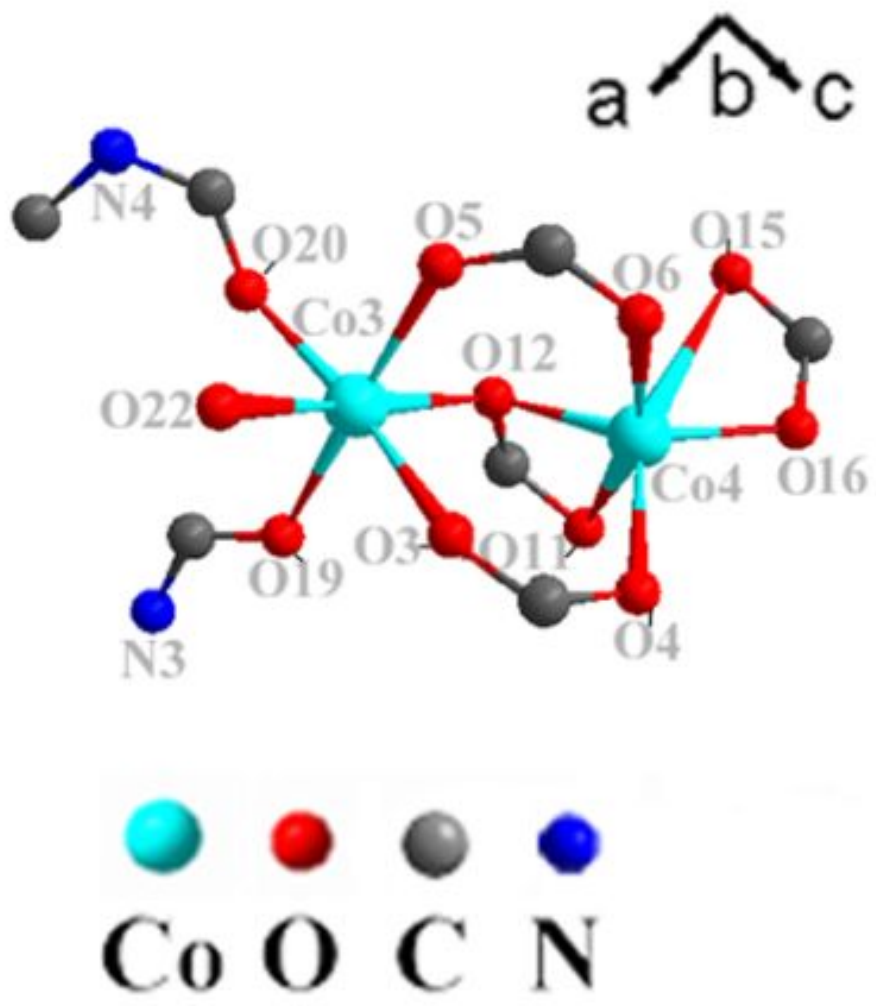

Figure S2. a) the asymmetric unit and b) the additional coordination environment of Co3 and Co4 atoms in BMM-12. 

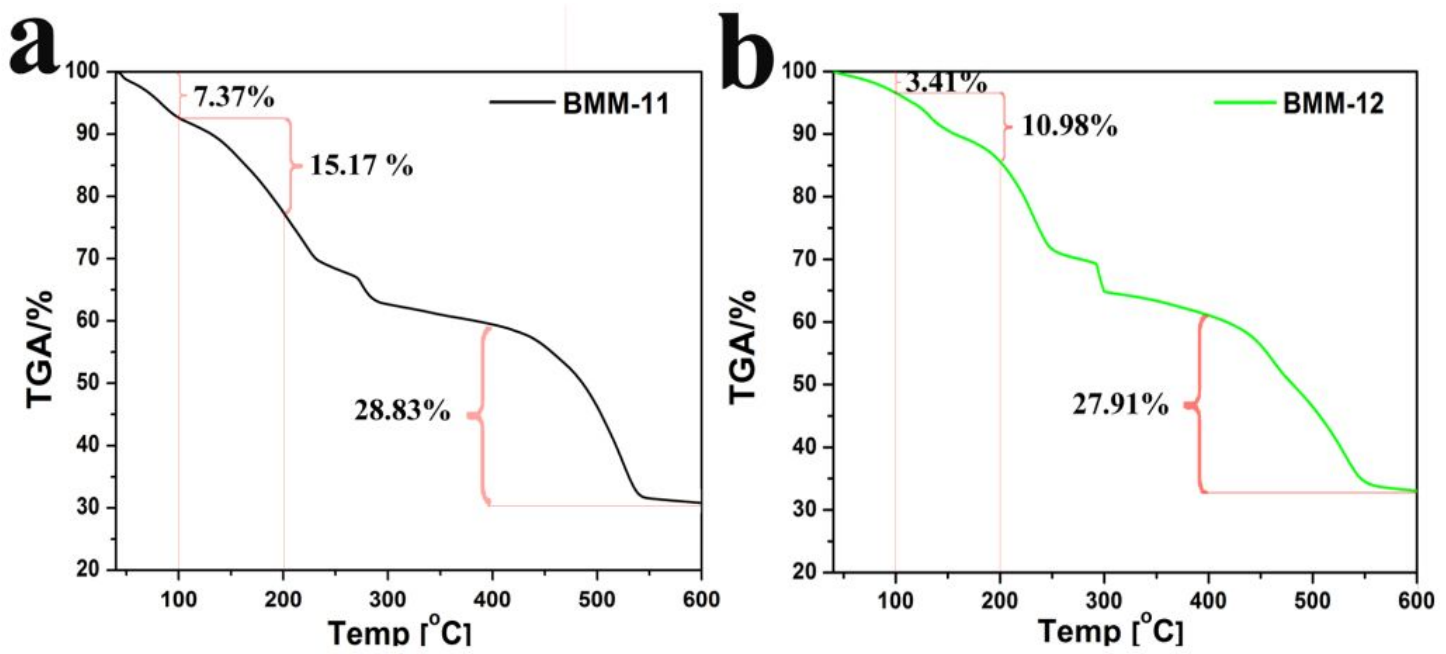

Figure S3. TGA data of a) BMM-11 and b) BMM-12.

The thermogravimetric analysis (TGA) curves of the pristine BMM-11/12 sample are conducted in the temperature range of $40-600{ }^{\circ} \mathrm{C}$ under a flow of nitrogen with a heating rate of $10{ }^{\circ} \mathrm{C} \mathrm{min}^{-1}$.

BMM-11 shows the first weight loss of 7.37 wt \% before $100{ }^{\circ} \mathrm{C}$ which can be attributed to the loss of the 2.9 free molecules $\mathrm{H}_{2} \mathrm{O}$ in sample and exhibits another weight loss of $\sim 15.17 \%$ between $100{ }^{\circ} \mathrm{C}$ and $200{ }^{\circ} \mathrm{C}$, corresponding to the loss of guest $1 \mathrm{DMA}$ and 0.28 DMF molecules. After $400{ }^{\circ} \mathrm{C}$, the main structure starts to collapse gradually. We thus learn that most of the pyrolyzed products are oxides and/or carbides in the temperature range of $400-600{ }^{\circ} \mathrm{C}$.

The same argument applies to BMM-12 which shows the first weight loss of 3.41 wt $\%$ before $100{ }^{\circ} \mathrm{C}$ which assigned to $0.57 \mathrm{MeCN}$ molecules, then exhibits another weight loss of $\sim 10.98 \%$ between $100{ }^{\circ} \mathrm{C}$ and $200{ }^{\circ} \mathrm{C}$; which assigned to loss of 1.29 NMF guest molecules. Finally, the main structure starts to collapse gradually after $400{ }^{\circ} \mathrm{C}$. 

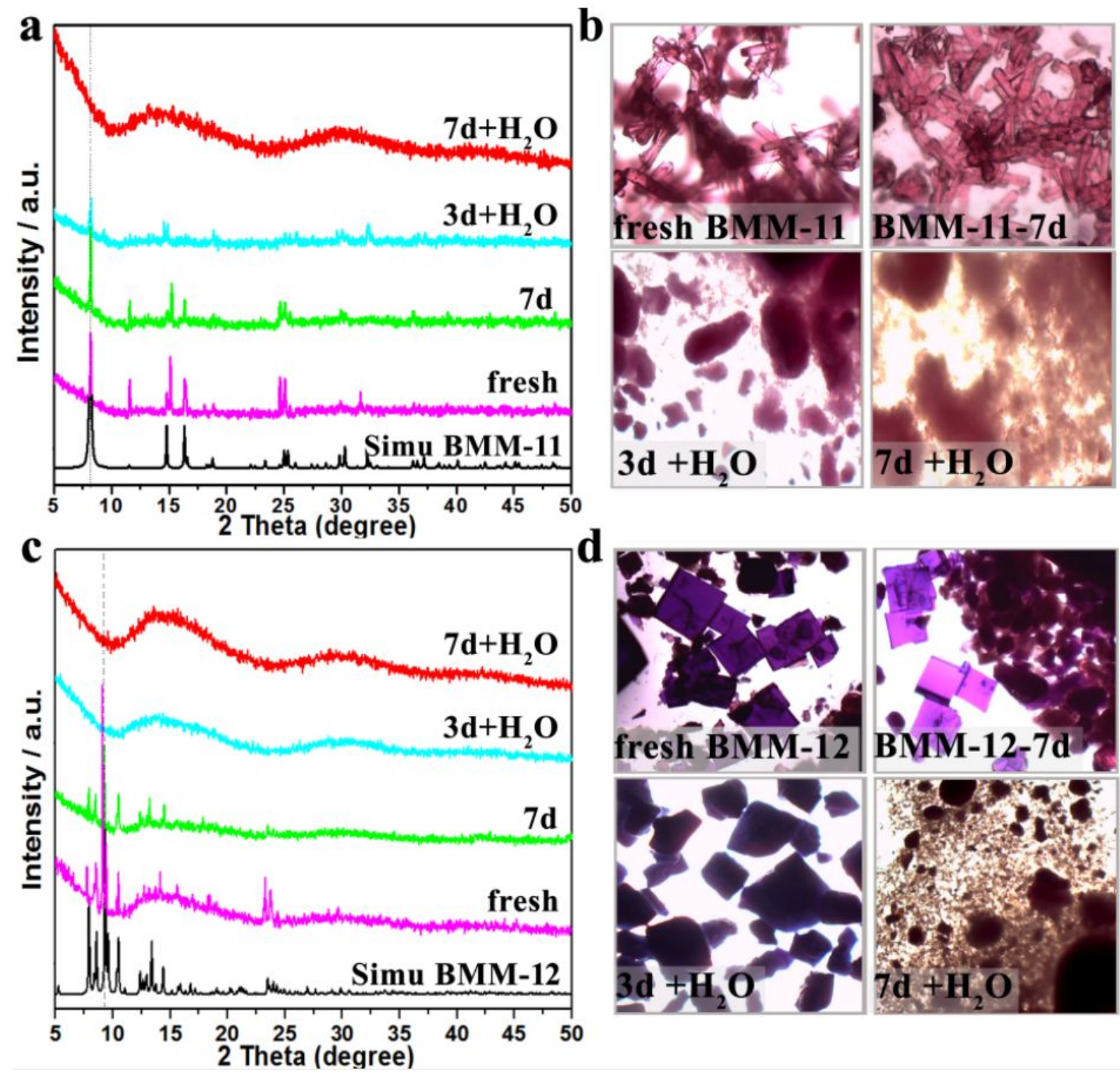

Figure S4. The PXRD patterns and optical microscopic images before and after water/mother liquor treatment for a-b) BMM-11; c-d) BMM-12.

As depicted in Figure S4, only BMM-11 is basically stable and maintains its PXRD pattern after immersion in water for 3 days, but all of these materials cannot maintain crystallinity for 7 days according to PXRD patterns. In addition, the crystals of BMM-11/12 are relatively stable in the mother liquor even for 7 days, indicating satisfying structural stability.. 

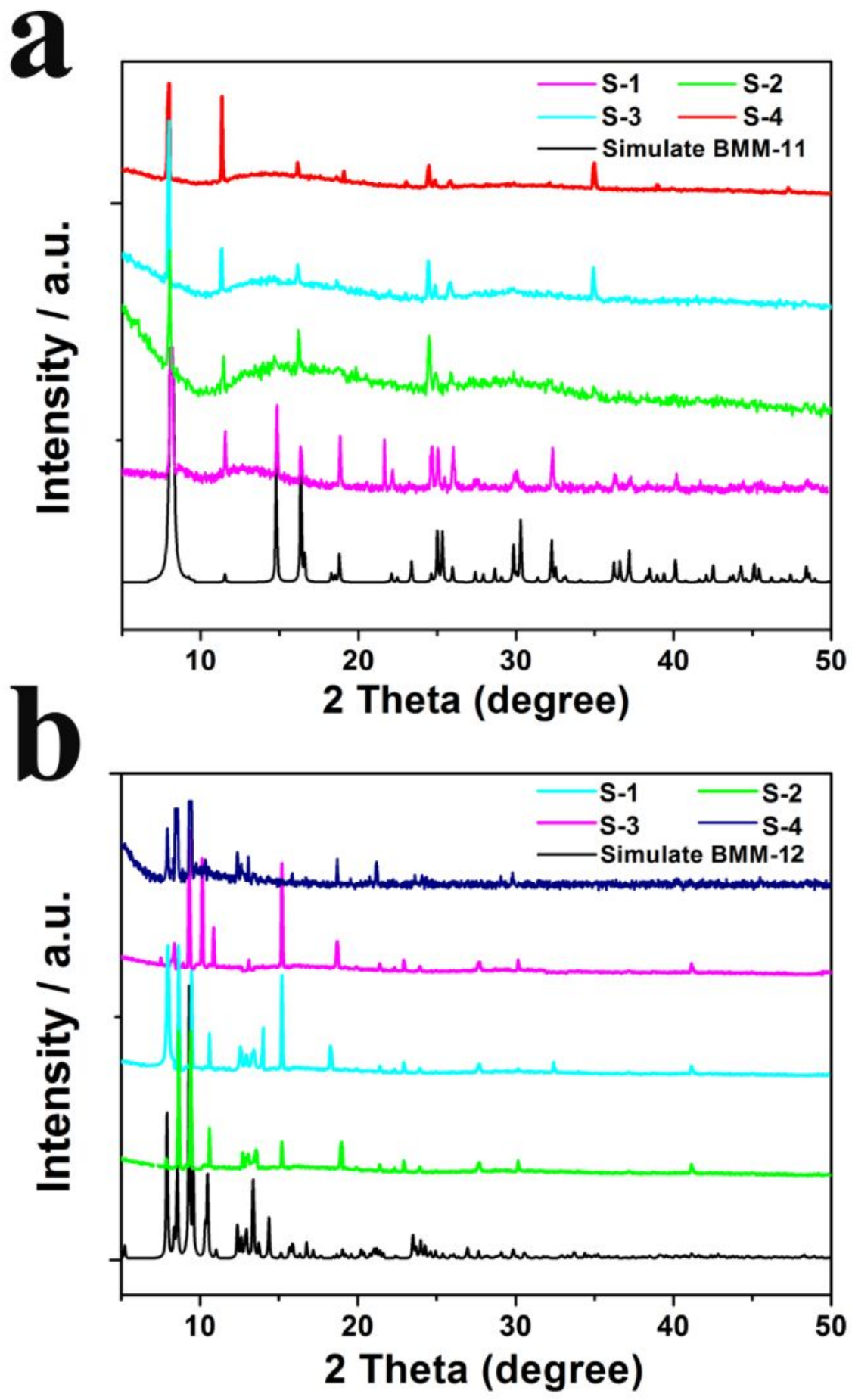

Figure S5. a) More XRD information about 4 different samples of BMM-11 and b) BMM-12 synthesized at different time. 

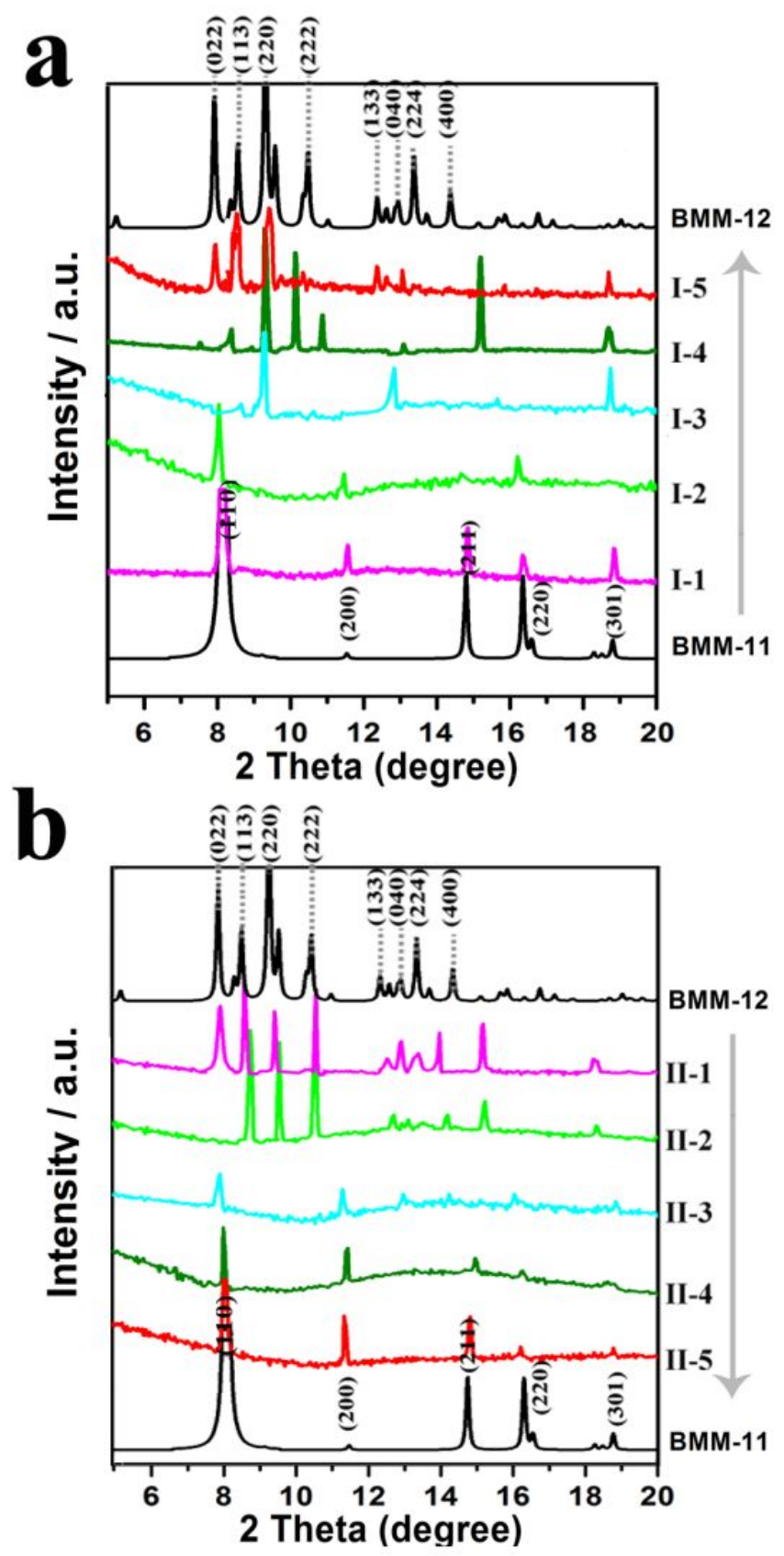

Figure S6. Detailed XRD information on structural conversion at $2 \theta$ value of $5-20^{\circ}$ for a) BMM-11 and b) BMM-12. 

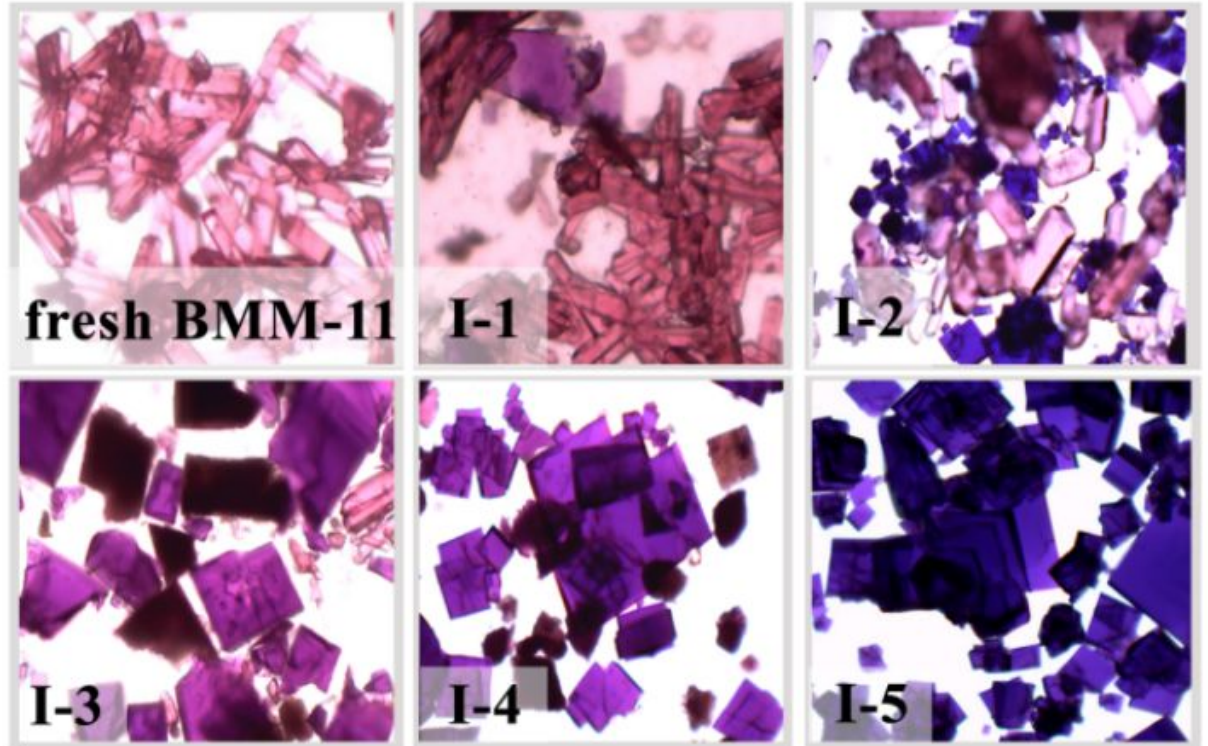

b TS-II BMM-12 to BMM-11

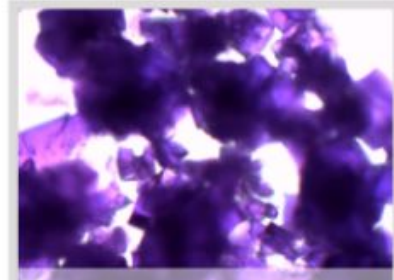

fresh BMM-12
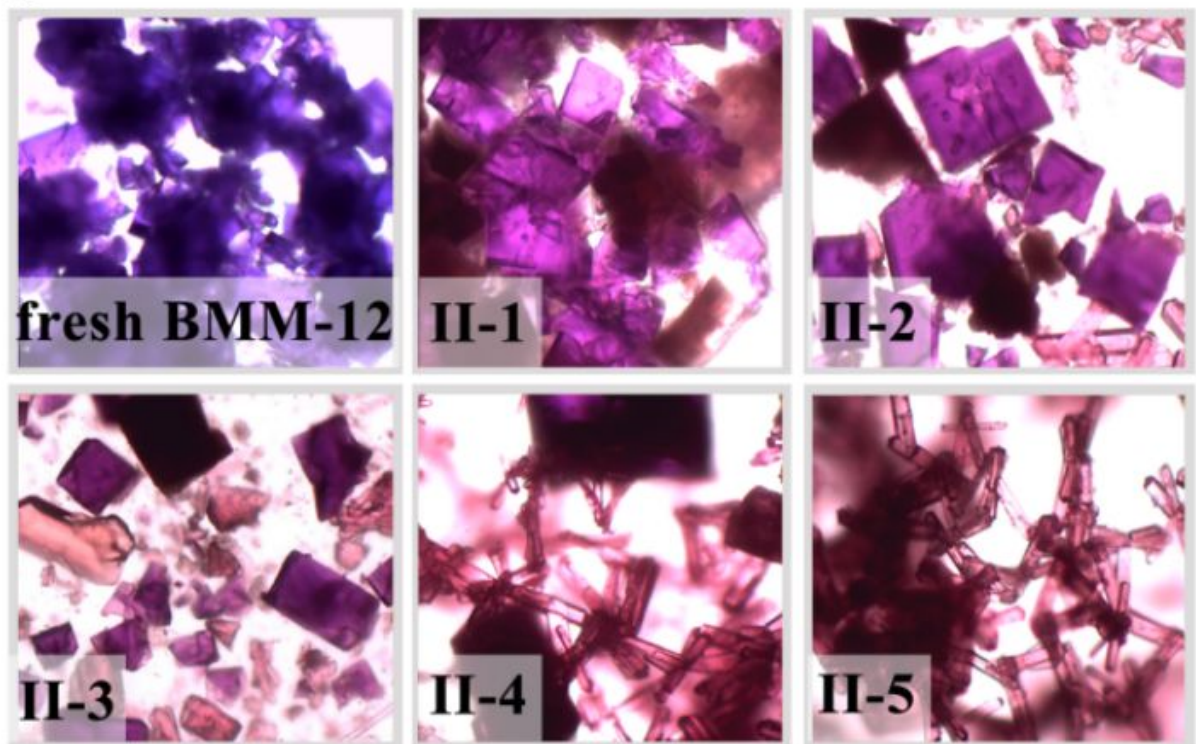

Figure S7. Optical microscopic images at different times (1-5 days) of transformation processes between BMM-11 and BMM-12. 


\section{Additional structure discussion of coordination environment in mutual crystal transformation process.}

2.1 Connected and cleavaged nodes.

\begin{tabular}{|c|c|c|c|c|c|c|}
\hline \multirow{2}{*}{ Items } & \multicolumn{6}{|c|}{ Coordinated O atoms in BMM-12 } \\
\hline Co1 & O1 & O2 & O7 & O9 & O10 & O14 \\
Co2 & O2 & O8 & O13 & O17 & O18 & O21 \\
Co3 & O3 & O5 & O12 & O19 & O20 & O22 \\
Co4 & O4 & O6 & O11 & O12 & O15 & O16 \\
\hline
\end{tabular}

Table S3. Coordinated O atoms in BMM-12.

For BMM-12, its asymmetric unit involves four independent $\mathrm{Co}(\mathrm{II})$ cations, two coordinated $\mathrm{H}_{2} \mathrm{O}$ molecules, four terminally coordinated NMF molecules.

$\mathrm{Co} 1$ atom coordinates to five carboxylate oxygens from three separate $\mathrm{H}_{4} \mathrm{BPTC}$ ligands $\left(\mathrm{O} 1\right.$ and $\mathrm{O} 2$ from one $\mathrm{H}_{4} \mathrm{BPTC}$ ligand, $\mathrm{O} 9$ and $\mathrm{O} 10$ from one $\mathrm{H}_{4} \mathrm{BPTC}$ ligand, $\mathrm{Co} 1$ and $\mathrm{Co} 2$ are further connected via $\mathrm{O} 7$ and $\mathrm{O} 8$ from another $\mathrm{H}_{4} \mathrm{BPTC}$ ligand; meanwhile one oxygen (O14) from NMF molecules.

$\mathrm{Co} 2$ atom coordinate to two carboxylate oxygens from two $\mathrm{H}_{4} \mathrm{BPTC}$ ligands $(\mathrm{O} 2, \mathrm{O} 8$ which connect $\mathrm{Co} 1$ and $\mathrm{Co} 2)$, meanwhile two oxygens $(\mathrm{O} 18, \mathrm{~N} 2),(\mathrm{O} 17, \mathrm{~N} 1)$ from two solvents (NMF); and $\mathrm{O} 21, \mathrm{O} 13$ from the solvent molecule $\mathrm{H}_{2} \mathrm{O}$.

$\mathrm{Co} 3$ atom coordinate to three carboxylate oxygens from three separate $\mathrm{H}_{4} \mathrm{BPTC}$ ligands (O3, O12 connect $\mathrm{Co} 3$ and $\mathrm{Co} 4)$. At the same time, two oxygens $(\mathrm{O} 19, \mathrm{~N} 3)$, $(\mathrm{O} 20, \mathrm{~N} 4)$ from two solvents (NMF); and $\mathrm{O} 22$ from one solvent molecule $\mathrm{H}_{2} \mathrm{O}$.

$\mathrm{Co} 4$ atom coordinateto six carboxylate oxygens from three $\mathrm{H}_{4} \mathrm{BPTC}$ ligands $(\mathrm{O} 15$, $\mathrm{O} 16$ from one $\mathrm{H}_{4} \mathrm{BPTC}$, O11, $\mathrm{O} 12$ from a $\mathrm{H}_{4} \mathrm{BPTC}$, $\mathrm{O} 4$, $\mathrm{O} 6$ from two separate $\mathrm{H}_{4} \mathrm{BPTC}$, and $\mathrm{O} 12$ connect $\mathrm{Co} 3$ and $\mathrm{Co} 4$ ).

Co1-Co2 and $\mathrm{Co} 3-\mathrm{Co} 4$ are connected respectively, which form a dual-core distorted polyhedron. 


\begin{tabular}{|c|c|c|}
\hline Items & Cleavaged nodes & Source \\
\hline \multirow{3}{*}{ Col } & $\mathrm{O} 1$ & $\mathrm{H}_{4} \mathrm{BPTC}$ \\
\hline & O9 & $\mathrm{H}_{4} \mathrm{BPTC}$ \\
\hline & $\mathrm{O} 10$ & $\mathrm{H}_{4} \mathrm{BPTC}$ \\
\hline \multirow{3}{*}{$\mathrm{Co} 2$} & O17 & NMF \\
\hline & $\mathrm{O} 18$ & NMF \\
\hline & $\mathrm{O} 21$ & $\mathrm{H}_{2} \mathrm{O}$ \\
\hline \multirow{3}{*}{$\mathrm{Co3}$} & O19 & NMF \\
\hline & $\mathrm{O} 20$ & NMF \\
\hline & $\mathrm{O} 22$ & $\mathrm{H}_{2} \mathrm{O}$ \\
\hline \multirow{3}{*}{$\mathrm{Co} 4$} & O11 & $\mathrm{H}_{4} \mathrm{BPTC}$ \\
\hline & $\mathrm{O} 15$ & $\mathrm{H}_{4} \mathrm{BPTC}$ \\
\hline & $\mathrm{O} 16$ & $\mathrm{H}_{4} \mathrm{BPTC}$ \\
\hline
\end{tabular}

Table S4. During transformation, the cleavaged nodes of BMM-12 and its ligand sources. 


\subsection{Axes.}

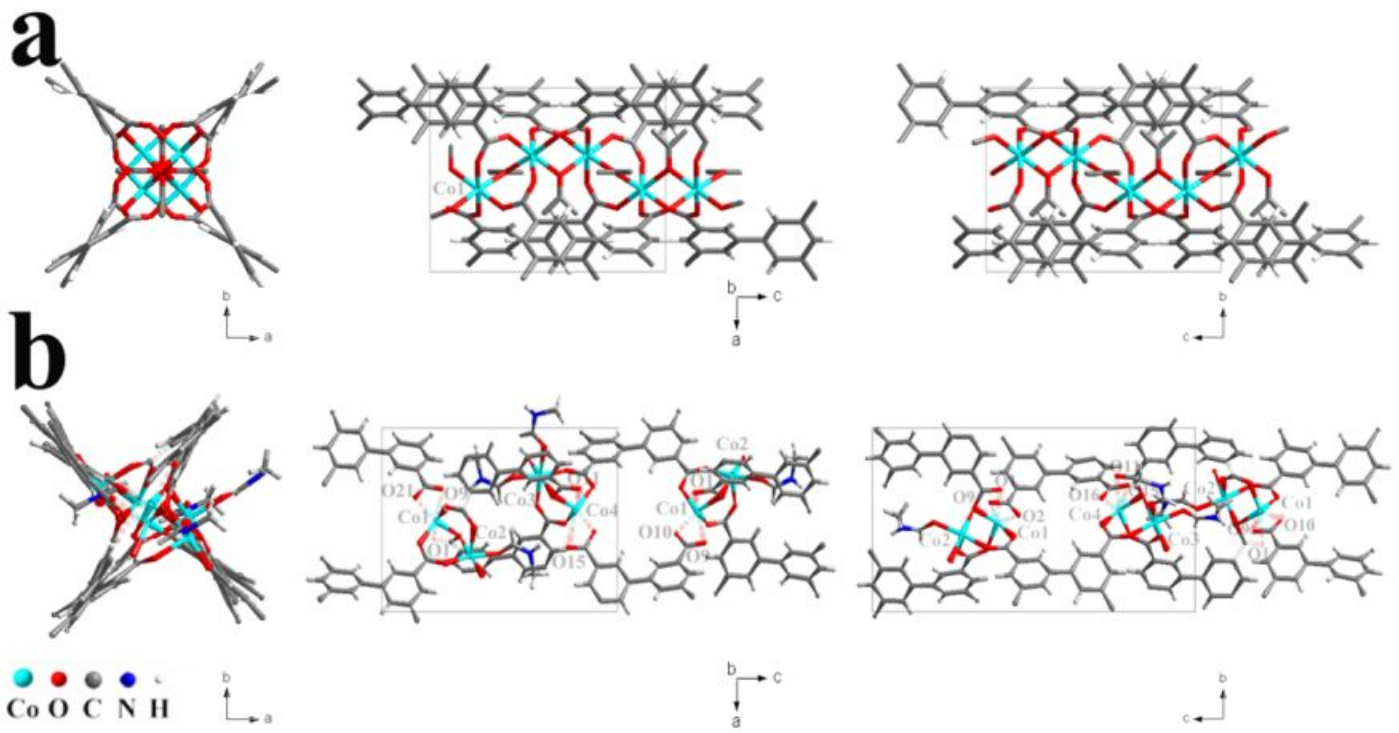

Figure S8. The coordination environment from different axes of a) BMM-11 and b)

BMM-12, respectively.

BMM-12 transforms to BMM-11.

As shown in Figure S8, the main structural feature of the BMM-11 is a one-dimensional chain-based network. However, we learn that the asymmetric unit of BMM-12 involves four types of $\mathrm{Co}$ atoms with the connected sequence of $\mathrm{Co} 1, \mathrm{Co} 2$; and $\mathrm{Co} 3, \mathrm{Co} 4$.

By observing the connection of the four adjacent Co atoms in BMM-11 (Fig. S8a) and BMM-12 (Fig. S8b) in three directions, when the dash-lined bonds are hypothetically broken in BMM-12, two neighboring cobalt centers will be transformed into a dual-core distorted polyhedron, which is further connected by others as 1D Co-O-Co-O chains.

In this case, structural torsion and stretch occur so that a successful transformation from BMM-12 to BMM-11 can be achieved. 


\subsection{Planes.}
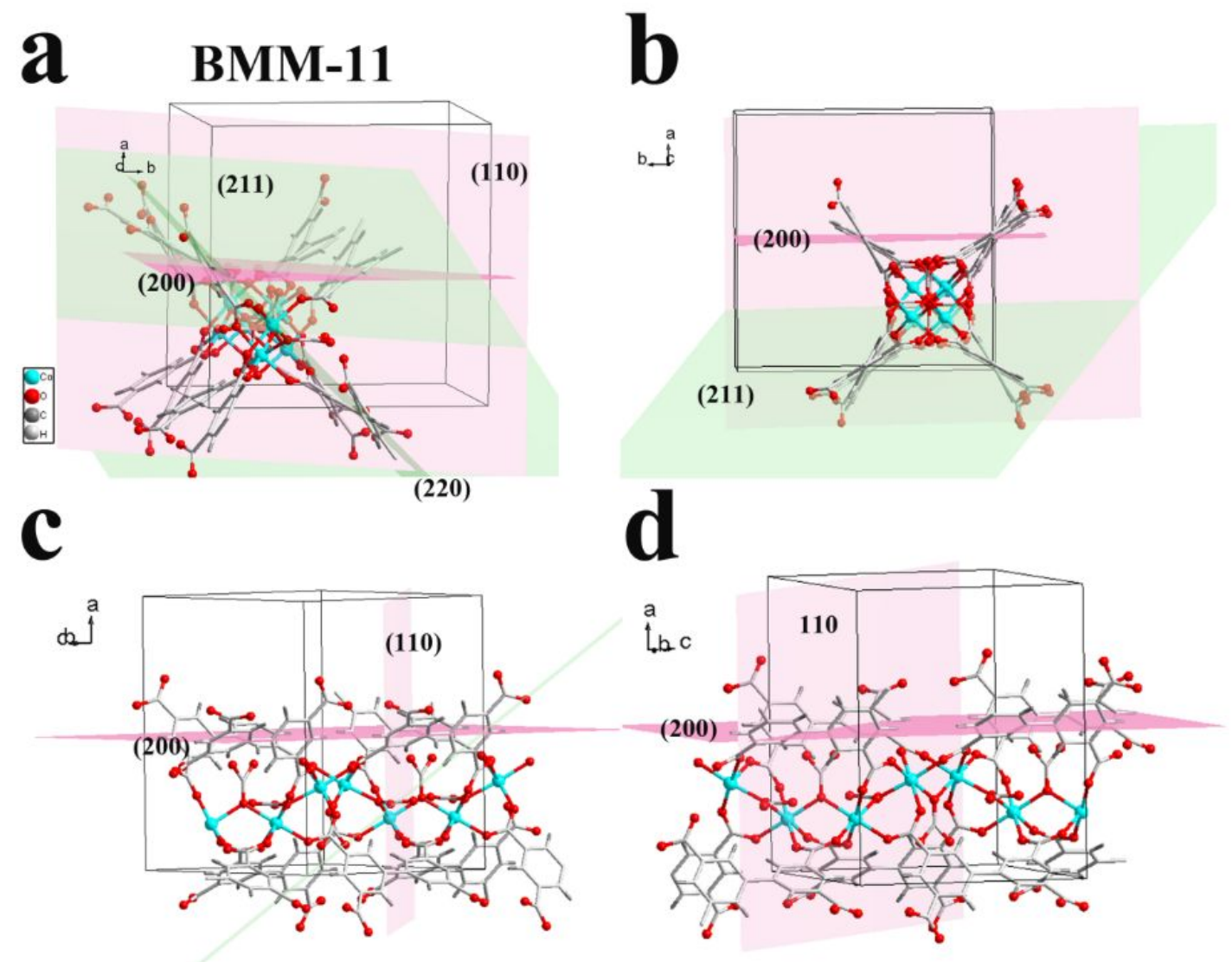

Figure S9. a-d) More specific discussion on the hypothetic conversion between different faces for the BMM-11.

BMM-11 transforms to BMM-12.

The main peaks of the BMM-11 of $8.26^{\circ}, 11.53^{\circ}, 14.79^{\circ}, 16.39^{\circ}, 18.86^{\circ}$, which can be assigned to the plane of (110), (200), (211), (220), (301). As shown in the Figure S9a, the (200) plane is marked with a deep red face which is perpendicular to the (110) plane and further divides the four $\mathrm{H}_{4} \mathrm{BPTC}$ ligands in the b-axis. Consistent with our speculation, the twist of the (200) plane transforms to the biphenyl environment of BMM-12. As shown in the Figure S9b, the (211) plane is marked as light green, which passes through $\mathrm{H}_{4}$ BPTC ligands, the Co atom (Co1) and oxygen atom $(\mathrm{O} 2, \mathrm{O} 4)$. The (220) plane is marked as deep green which just bisect the diagonal of the frame. In summary, the four main plane of BMM-11 are transformed into to those of the BMM-12 through the complex transition state[1]. 


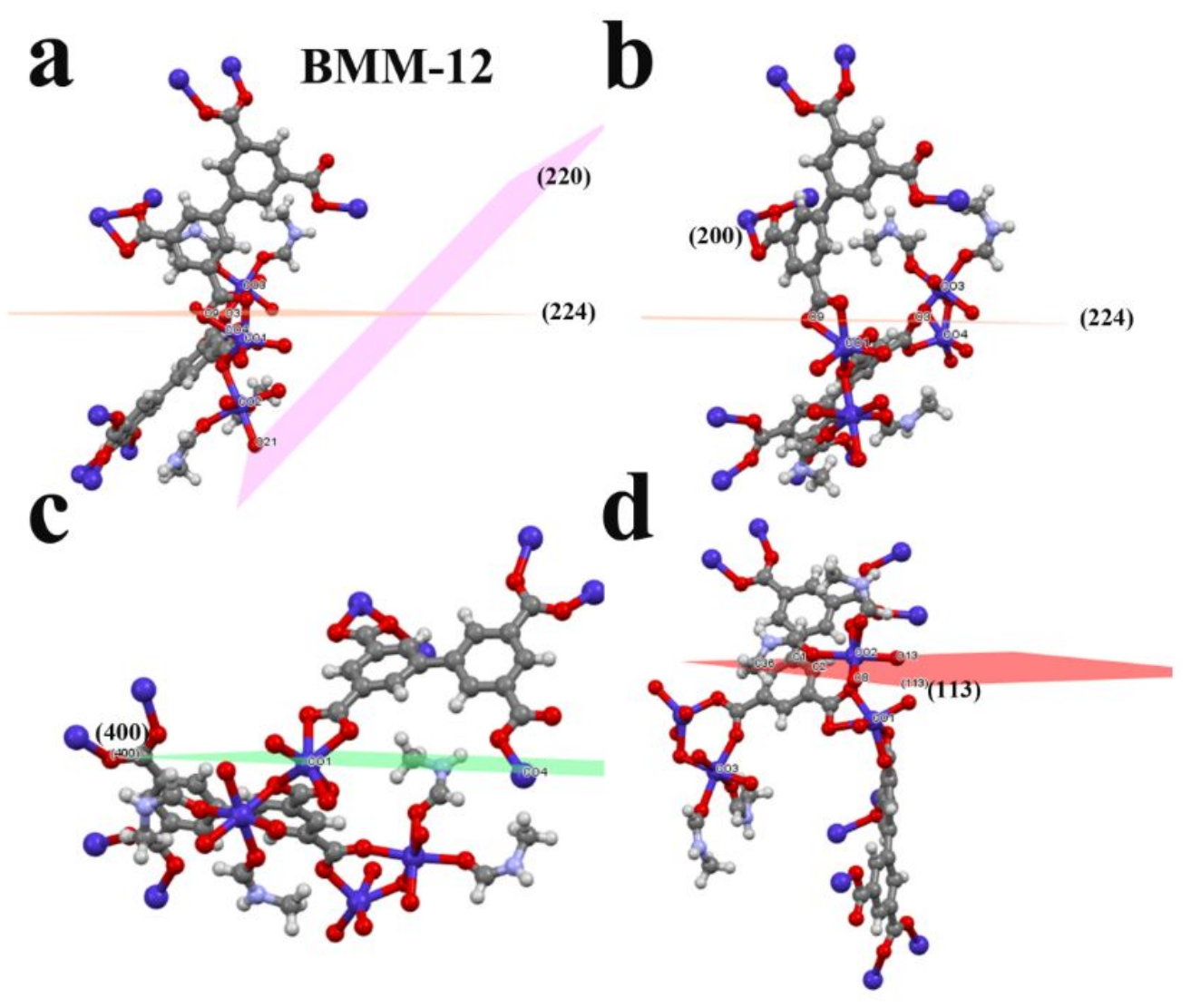

Figure S10. a-d) More specific faces for BMM-12. 
3. $\mathrm{CO}_{2}$ isotherms.

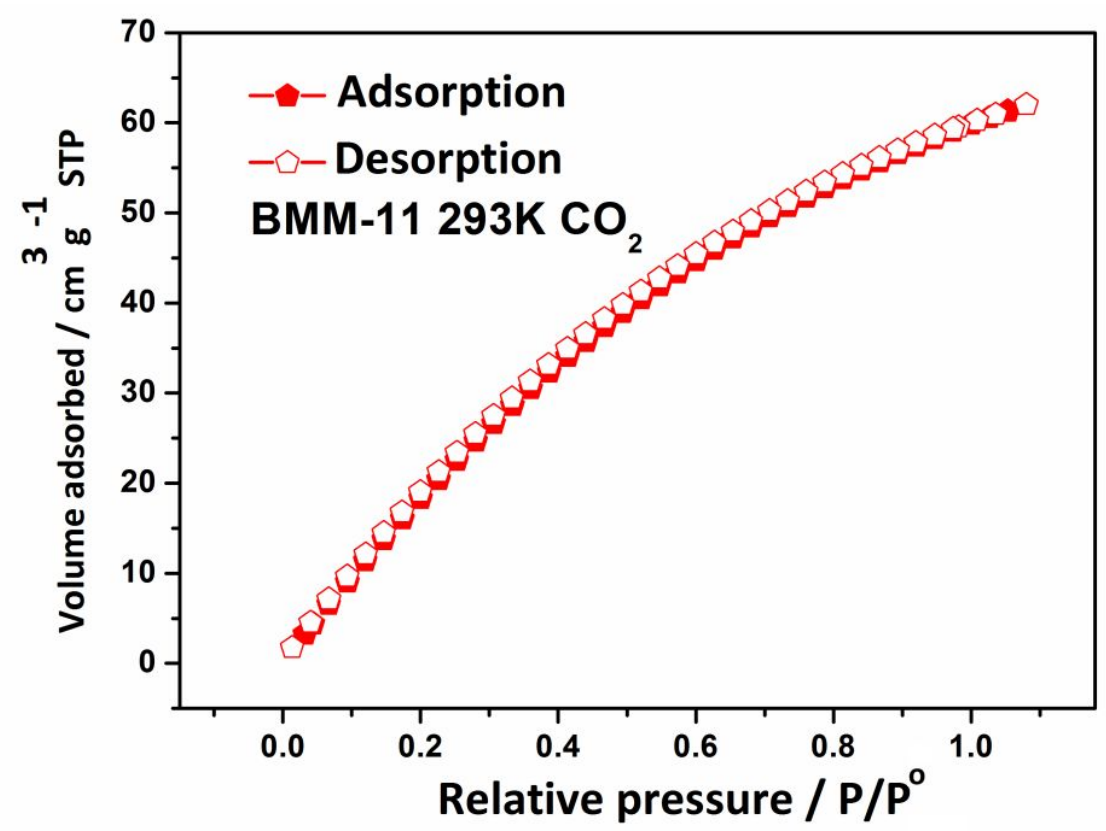

Figure S11. $\mathrm{CO}_{2}$ isotherms of BMM-11 in 293K. 
4. Additional structure transformation during OER process.
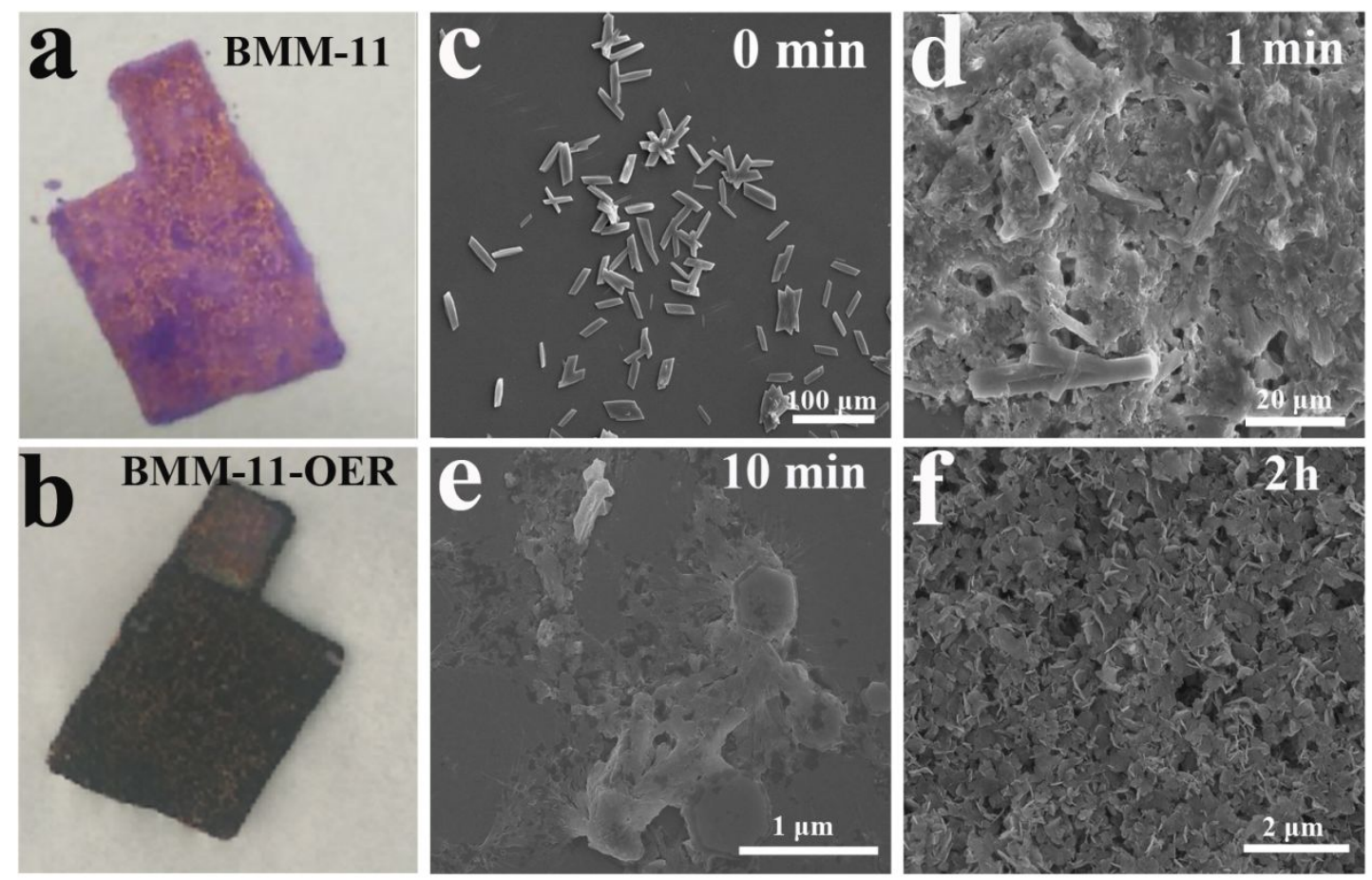

Figure S12. a-b) Structural and morphological transformation during OER reaction for BMM-11; c-f) SEM images of BMM-11 after different electrolyzing time. 

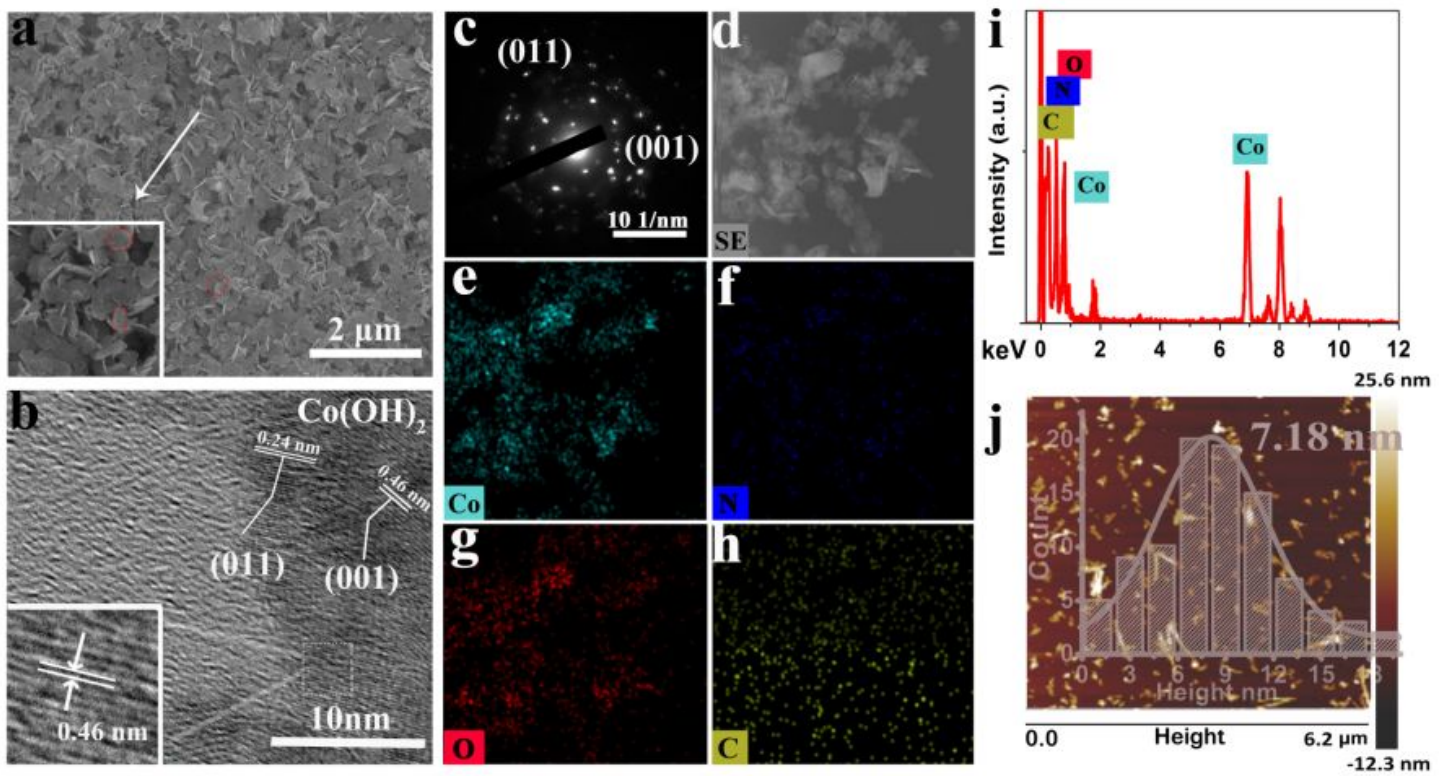

Figure S13. a) SEM images of BMM-12-OER; b) HRTEM image of BMM-12-OER where the planes of (001) and (011) are assigned to $\mathrm{Co}(\mathrm{OH})_{2}$; c) Selected-area electron diffraction (SAED) of BMM-12-OER; d) HRTEM image and e-h) Elemental mappings of Co, N, O, C (scale bar, $100 \mathrm{~nm}$ ). i) EDS pattern of BMM-12-OER; j) AFM profile of BMM-12-OER. 
Table S5. The Co, O, C and N element contents of BMM-11/12-OER catalyst (in wt $\%)$.

\begin{tabular}{|c|c|c|c|c|}
\hline Catalyst & Co(wt\%) & O(wt\%) & C (wt\%) & N(wt\%) \\
\hline BMM-11-OER & 30.37 & 61.53 & 6.04 & 2.06 \\
\hline BMM-12-OER & 32.79 & 58.36 & 5.90 & 2.95 \\
\hline
\end{tabular}



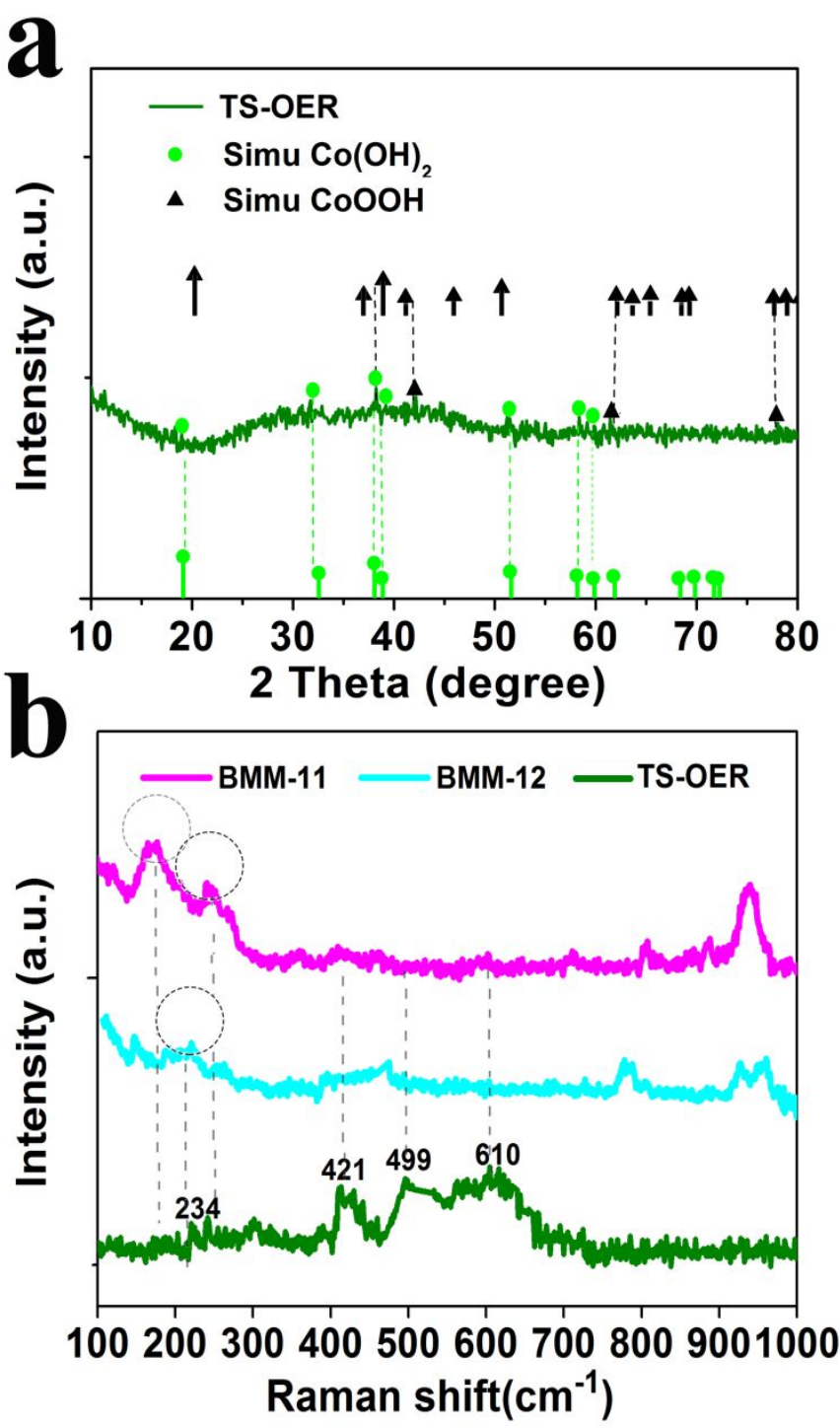

Figure S14. a) XRD patterns and b) Raman data of TS-OER. 

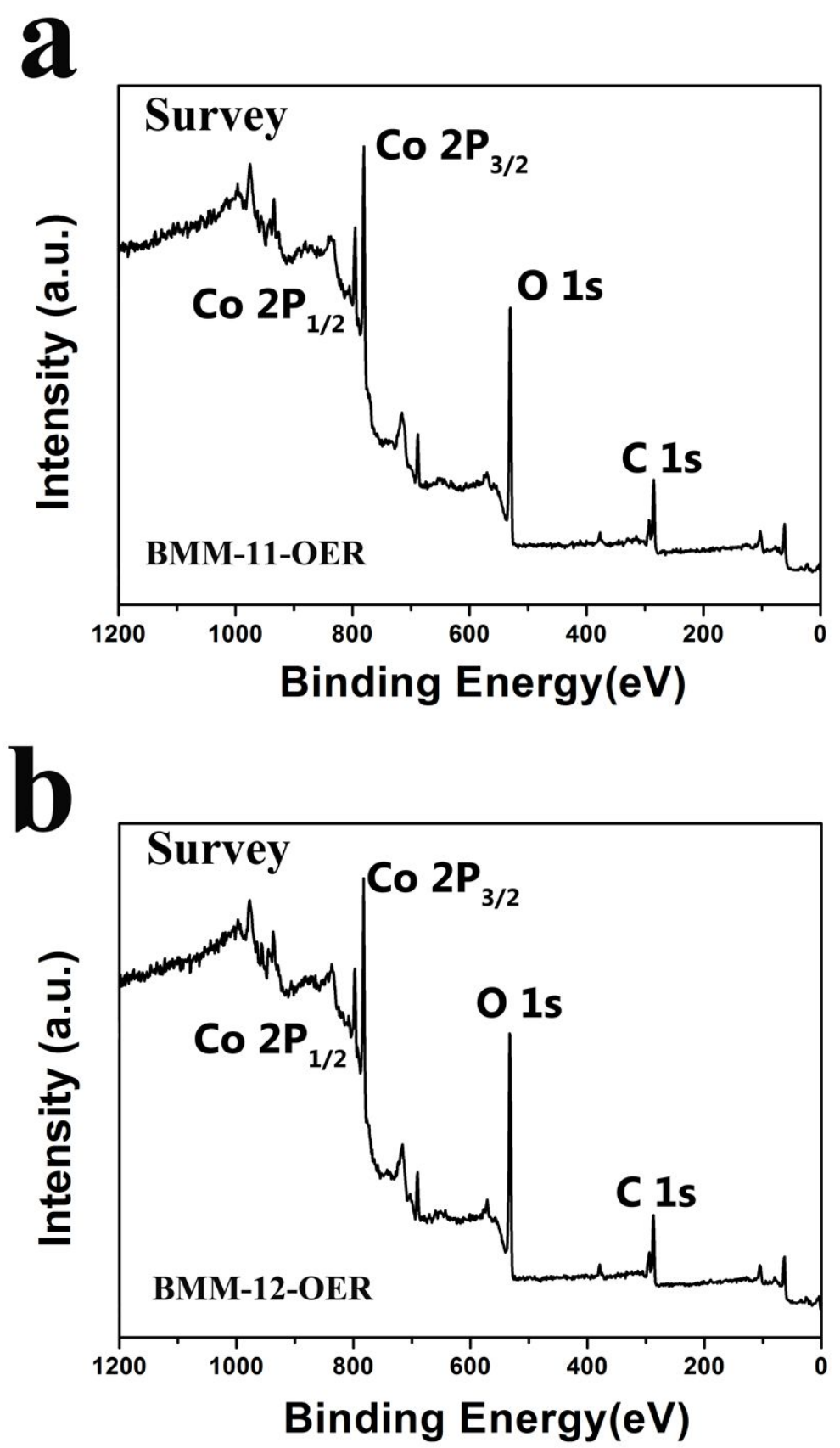

Figure S15. Full XPS surveys of a) BMM-11-OER and b) BMM-12-OER. 

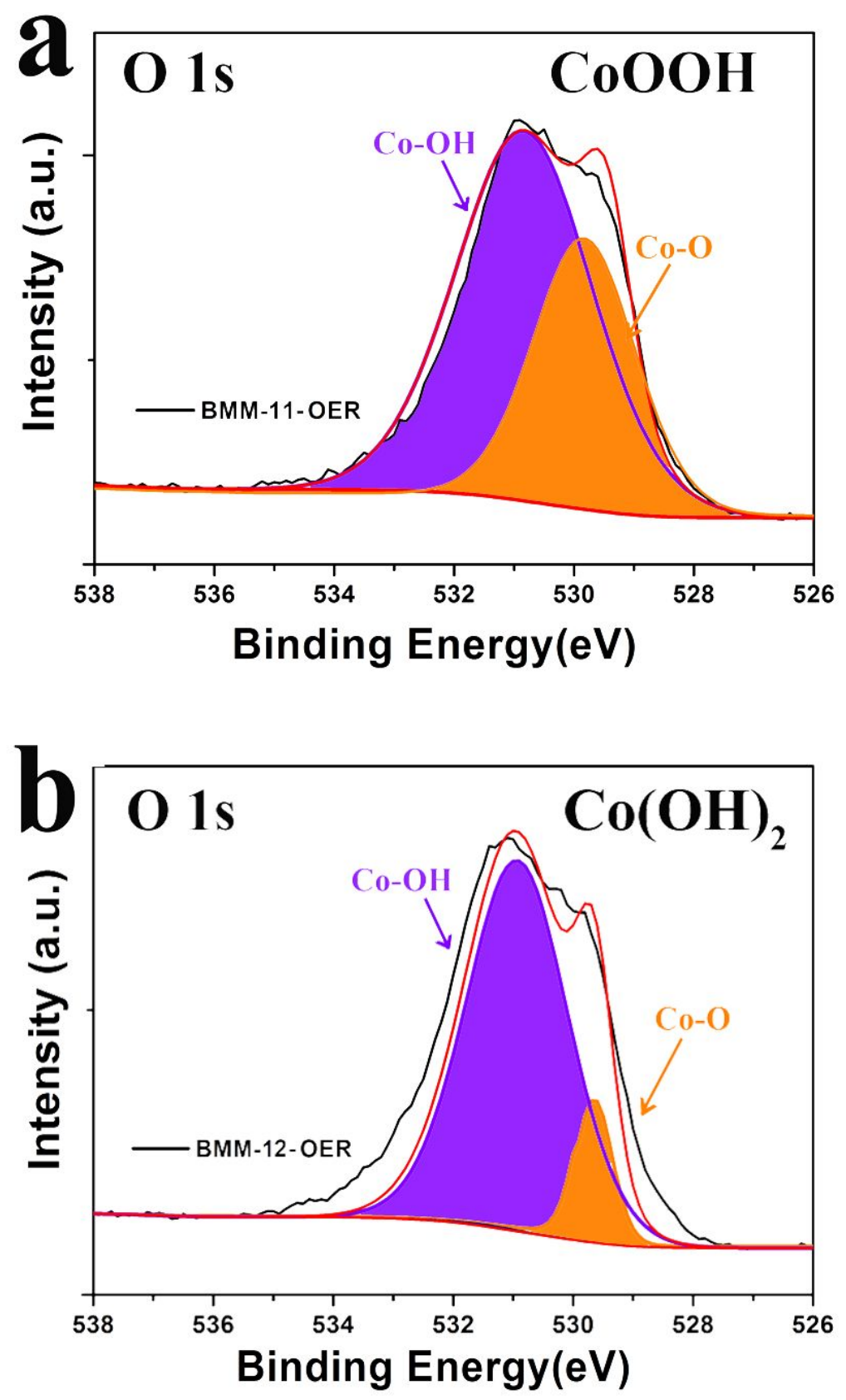

Figure S16. The XPS spectra of O1s of a) BMM-11-OER and b) BMM-12-OER. 


\section{Electrochemical Measurement}

All potentials are transferred to the reversible hydrogen electrode (RHE) scale by the following equation:

$\mathrm{E}_{\mathrm{RHE}}=\mathrm{E}_{\mathrm{Ag} / \mathrm{AgCl}}+(0.059 * \mathrm{pH})+0.1981, \mathrm{E}_{\mathrm{RHE}}=\mathrm{E}_{\mathrm{Hg} / \mathrm{HgO}}+(0.059 * \mathrm{pH})+0.2415^{[2,3]}$

The overpotential $(\eta)$ is calculated as follows:

$\eta=E_{(v s . ~ R H E)}-1.23$,

accordingto $\mathrm{O}_{2} / \mathrm{H}_{2} \mathrm{O}$ equilibrium (1.23 V vs. RHE).

The Tafel slope is transferred according to Tafel equation as follows:

$\eta=b \cdot \log \left(j / j_{0}\right)$.

The Faradaic efficiency $(\varepsilon)$ is calculated by theequation as follows: ${ }^{[4]}$

$\varepsilon=\mathrm{I}_{\mathrm{r}} /\left(\mathrm{I}_{\mathrm{d}} \cdot \mathrm{N}_{\mathrm{c}}\right)$,

RRDE where $I_{r}$ is the ring current, $I_{d}$ is the disk current, and $N_{c}$ is the current collection efficiency. At the same configuration, the $\mathrm{IrO}_{2}$ thin-filmelectrode is 0.2 . $\mathrm{IrO}_{2}$ is considered to be an excellent catalyst without other oxidation reactions in the process of oxygen evolution, close to $100 \%$ Faraday efficiency. So we choose the $\mathrm{IrO}_{2}$ thin-film electrode to calibrate the collection efficiency of the RRDE. Moreover, to calculate the Faradaic efficiency of the system, the disk electrodecurrent is $200 \mu \mathrm{A}$ $\left(\sim 1 \mathrm{~mA} \mathrm{~cm}^{-2}\right)$. This current is enough large to measure $\mathrm{O}_{2}$ production and to ignore local saturation and bubble formation influence at the disk electrode ${ }^{[5]}$.

The electron transfer number $(\mathrm{N})$ can be calculatedfrom $\mathrm{I}_{\mathrm{d}}$ and $\mathrm{I}_{\mathrm{r}}$ of RRDE:

$\mathrm{N}=4 * \mathrm{I}_{\mathrm{d}} /\left(\mathrm{I}_{\mathrm{d}}+\mathrm{I}_{\mathrm{r}} / \mathrm{N}_{\mathrm{c}}\right)$. 

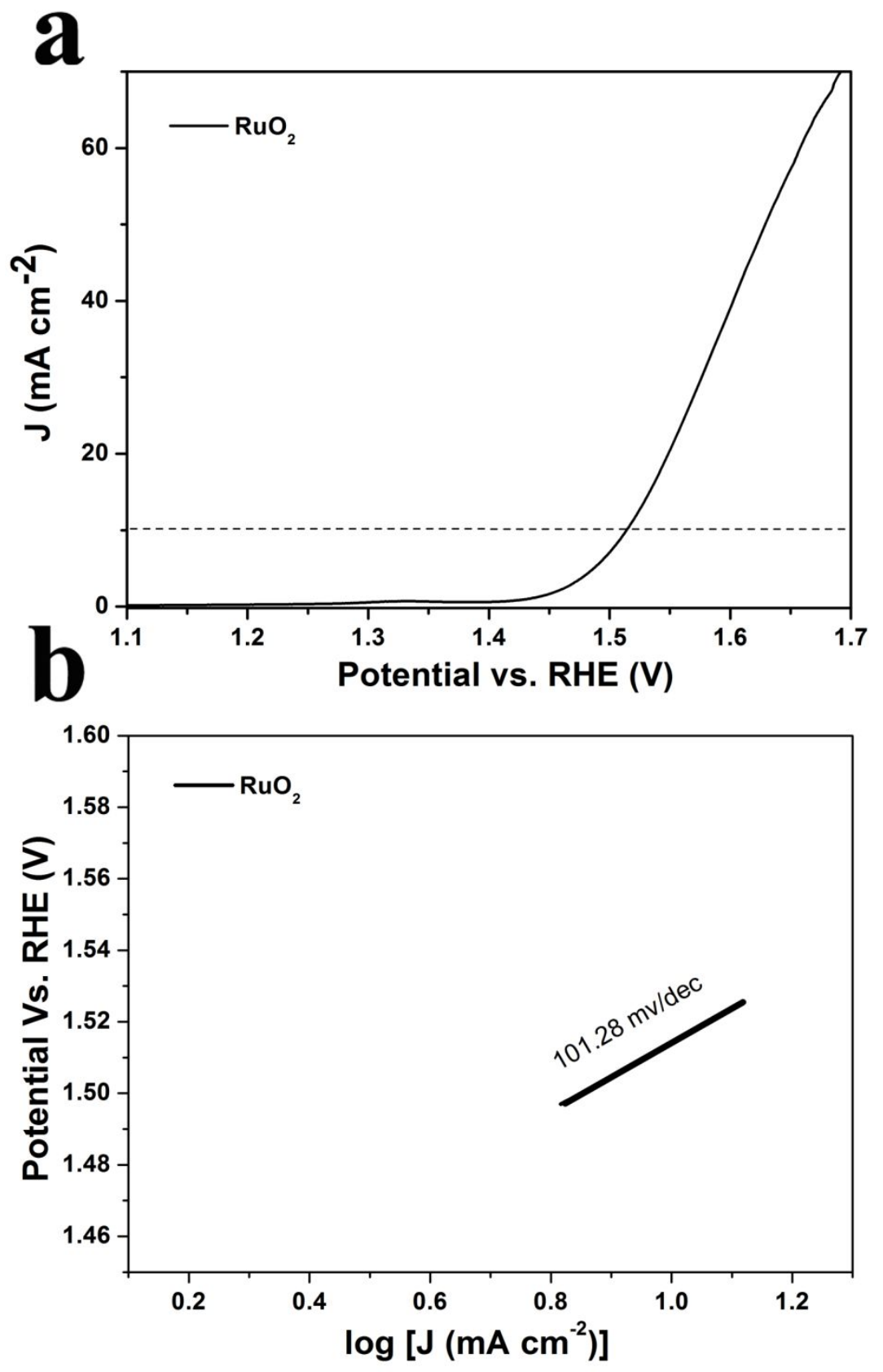

Figure S17. a) The OER polarization curves and b) the corresponding Tafel plots of $\mathrm{RuO}_{2}$. 


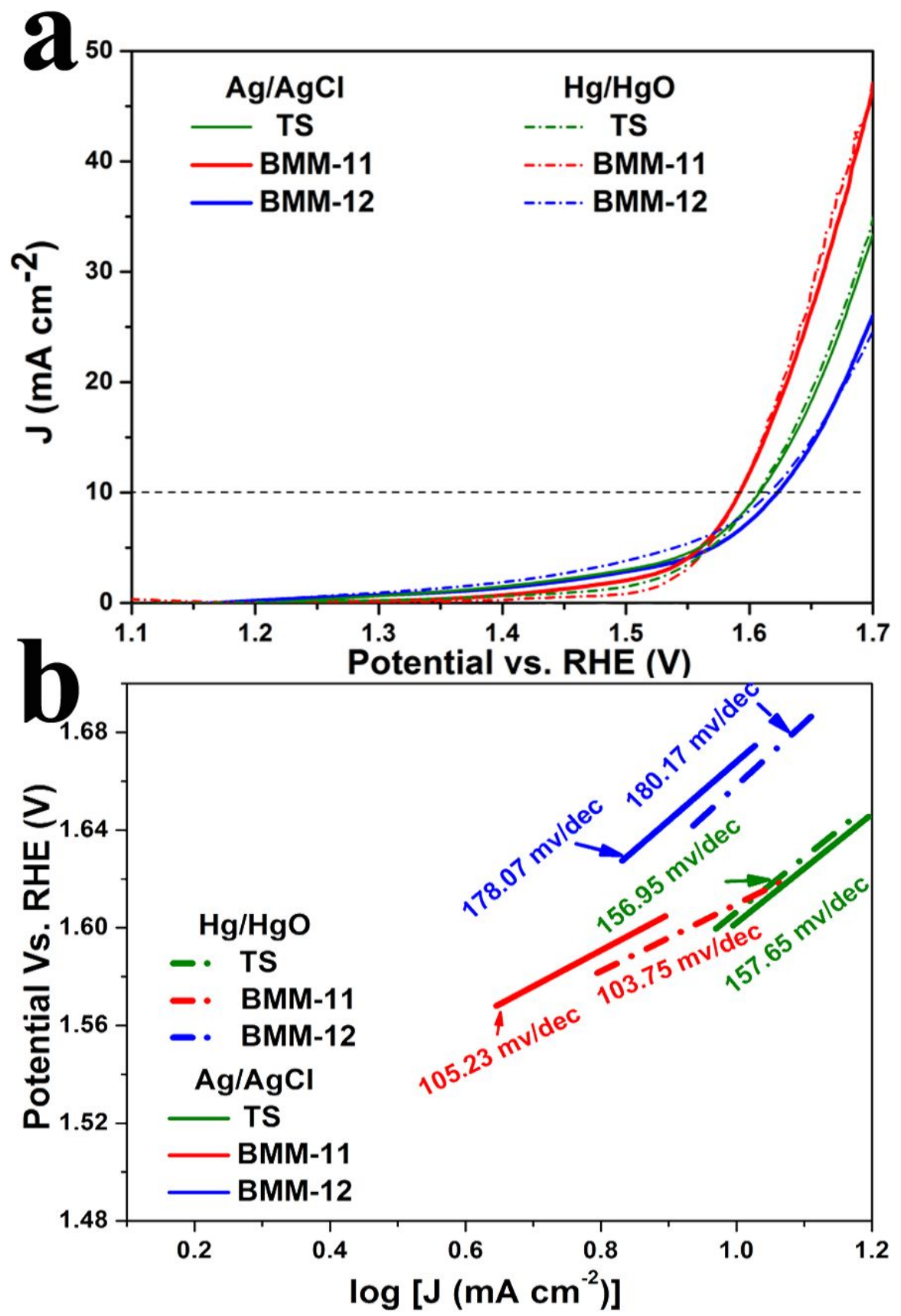

Figure S18. a) The OER polarization curves and b) the corresponding Tafel plots of BMM-11, BMM-12, and TS in $1.0 \mathrm{M} \mathrm{KOH}$ electrolyte $(\mathrm{Hg} / \mathrm{HgO}$ as well as $\mathrm{Ag} / \mathrm{AgCl}$ as the reference electrodes). 

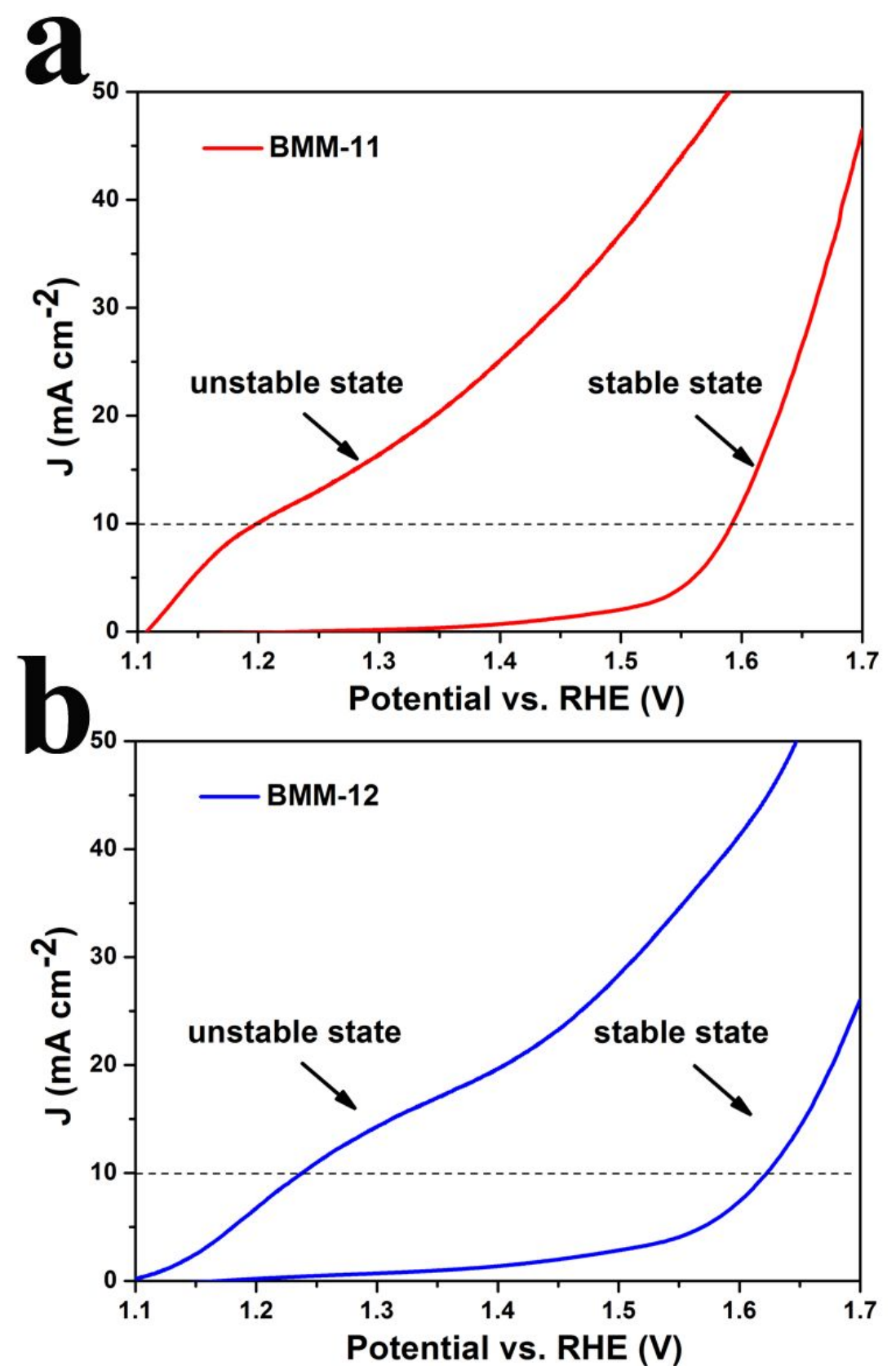

Figure S19. LSV curves from an unstable state to a stable state of a) BMM-11 and b) BMM-12. 
$\mathbf{a}$

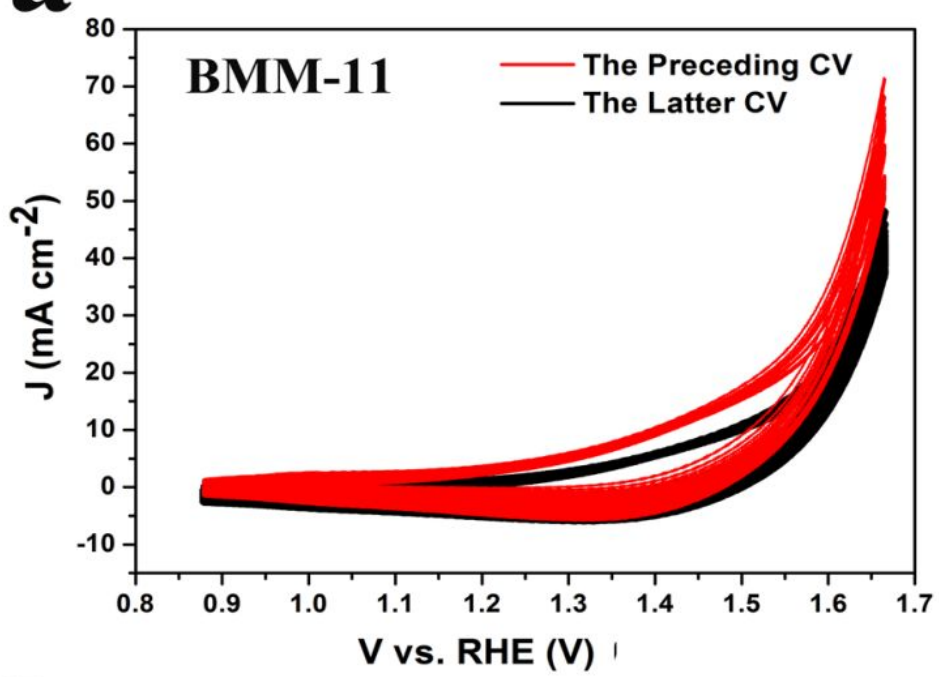

b
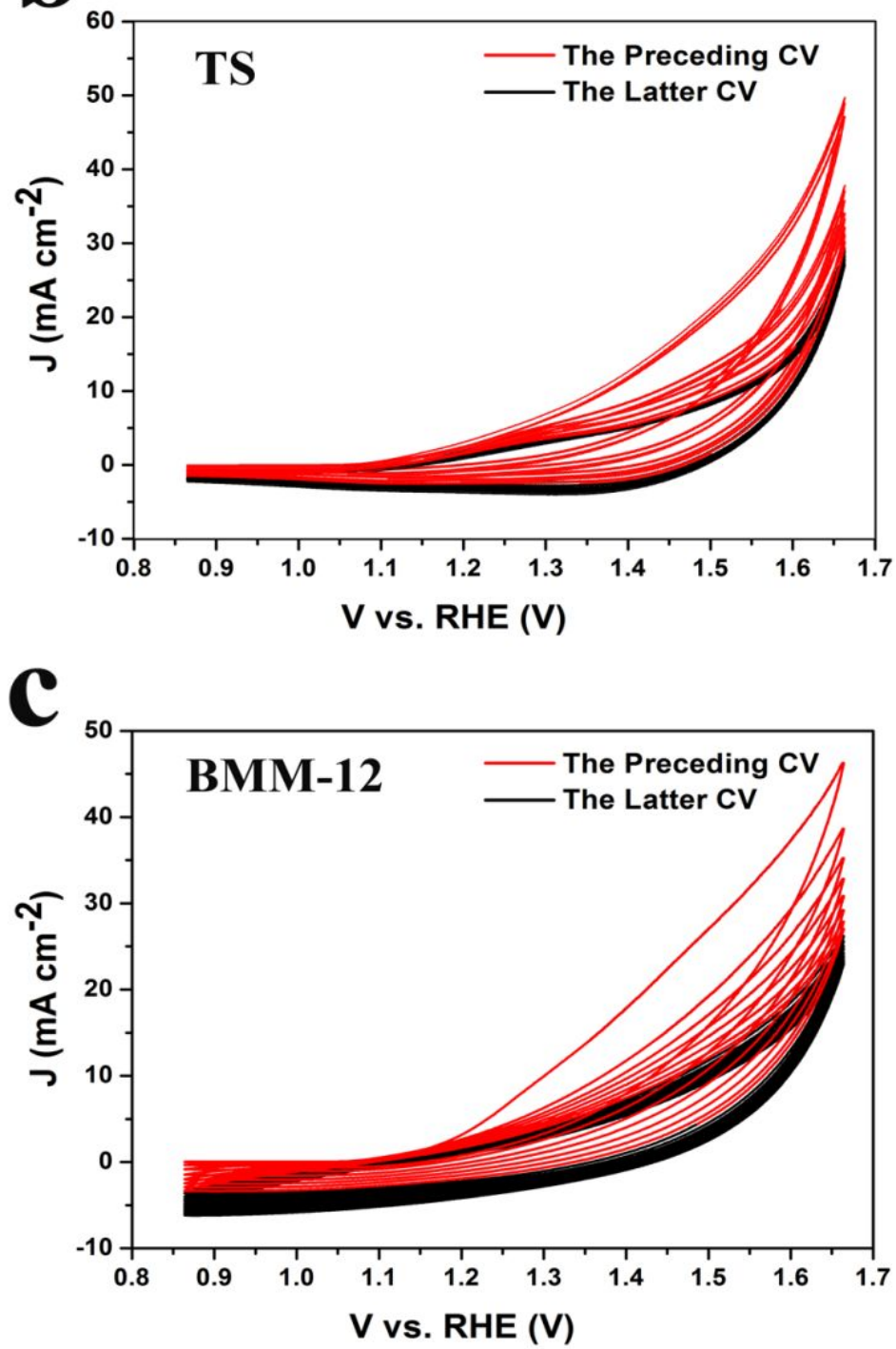

Figure S20. CV curves of a) BMM-11, b) TS and c) BMM-12. 


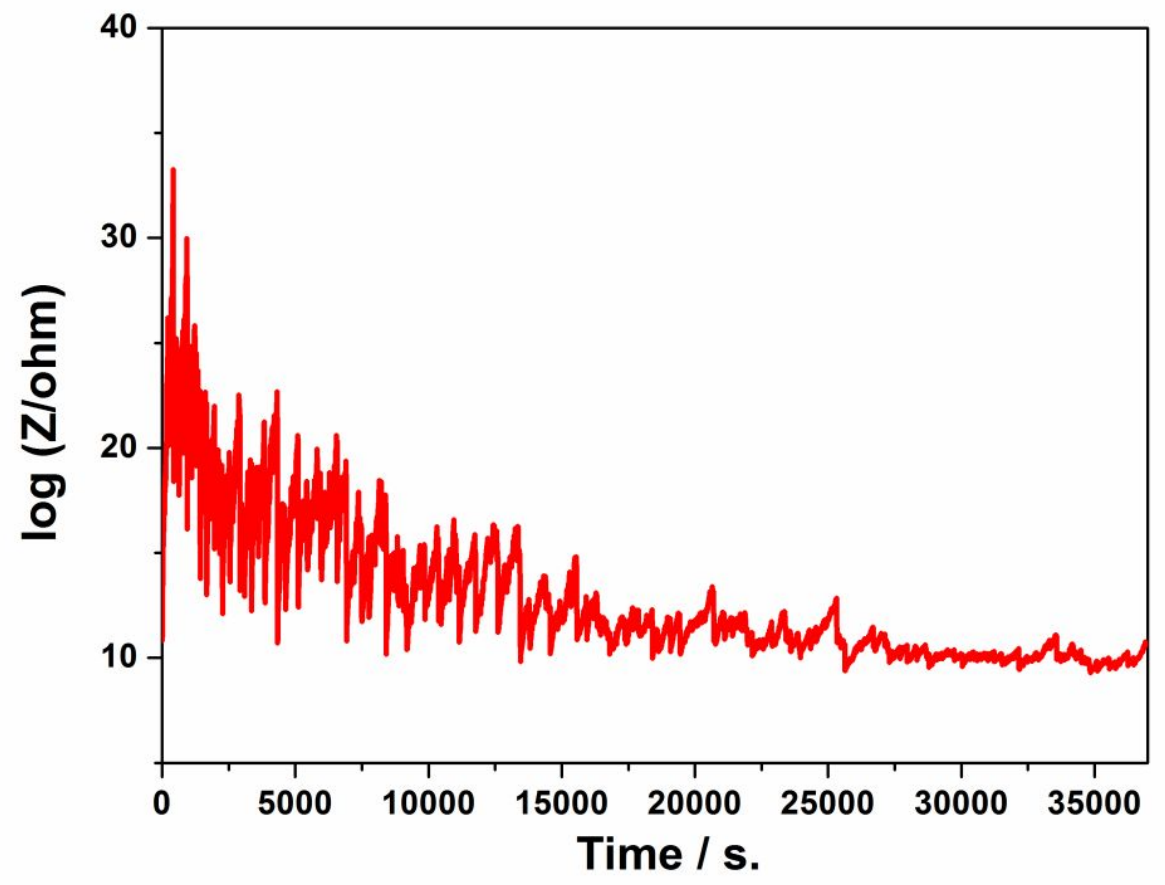

Figure S21. IMP-t of the BMM-11. 

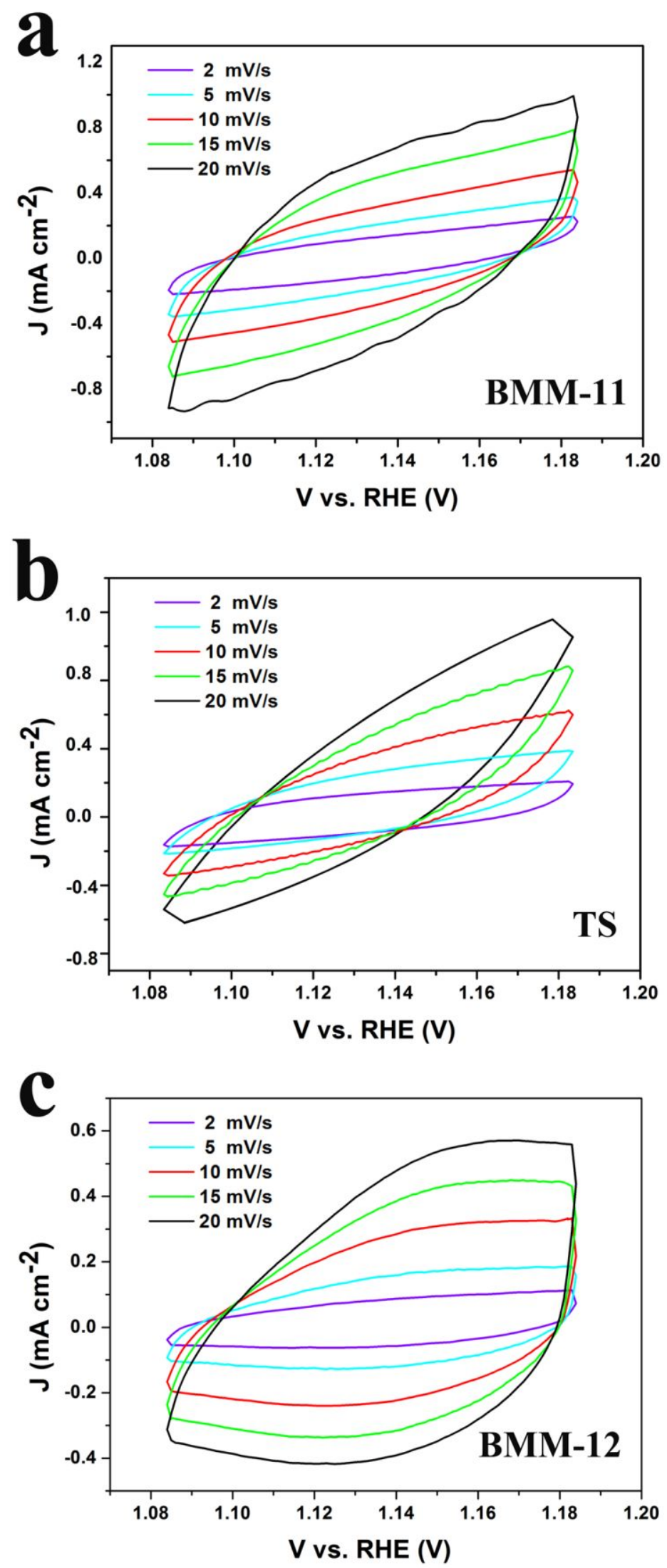

Figure S22. The double ayer capacitance $\left(\mathrm{C}_{\mathrm{dl}}\right)$ is calculated from the cyclic voltammograms of the a) BMM-11; b) TS; and c) BMM-12. 

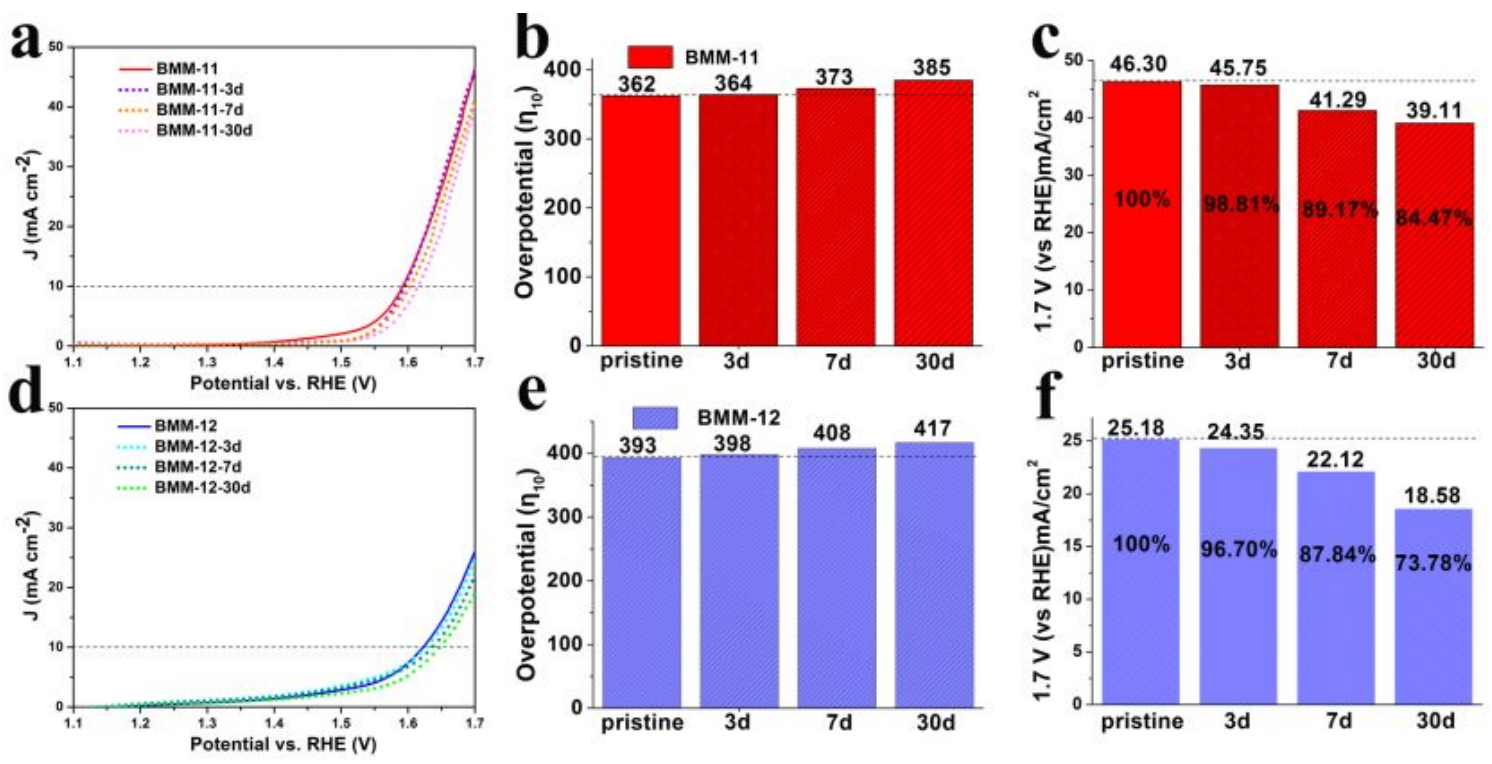

Figure S23. LSV curves of a) BMM-11 and d) BMM-12. Overpotential and retained current density percentage of the same samples which are placed for 3, 7 and 30 days to obtain the recyclability, as shown in b-c) for BMM-11 and e-f) for BMM-12.

\begin{tabular}{|c|c|c|c|c|}
\hline Catalyst BMM-11 & pristine & 3d & 7d & 30d \\
\hline$\eta_{10} / \mathrm{mV}$ & 362 & 364 & 373 & 385 \\
\hline $\begin{array}{c}1.7 \mathrm{~V}(\mathrm{vs} \mathrm{RHE}) \\
\mathrm{mA} / \mathrm{cm}^{2}\end{array}$ & 46.30 & 45.75 & 41.29 & 39.11 \\
\hline Catalyst BMM-12 & pristine & $\mathbf{3 d}$ & $\mathbf{7 d}$ & $\mathbf{3 0 d}$ \\
\hline$\eta_{10} / \mathrm{mV}$ & 393 & 398 & 408 & 417 \\
\hline $\begin{array}{c}1.7 \mathrm{~V}(\mathrm{vs} \mathrm{RHE}) \\
\mathrm{mA} / \mathrm{cm}^{2}\end{array}$ & 25.18 & 24.35 & 22.12 & 18.58 \\
\hline
\end{tabular}

Tables S6. BMM-11/12 in $1 \mathrm{M} \mathrm{KOH}$ at $10 \mathrm{~mA} / \mathrm{cm}^{2}$ : Summarization of OER performance of our materials in this work which are placed for 3, 7 and 30 days to obtain the recyclability. 


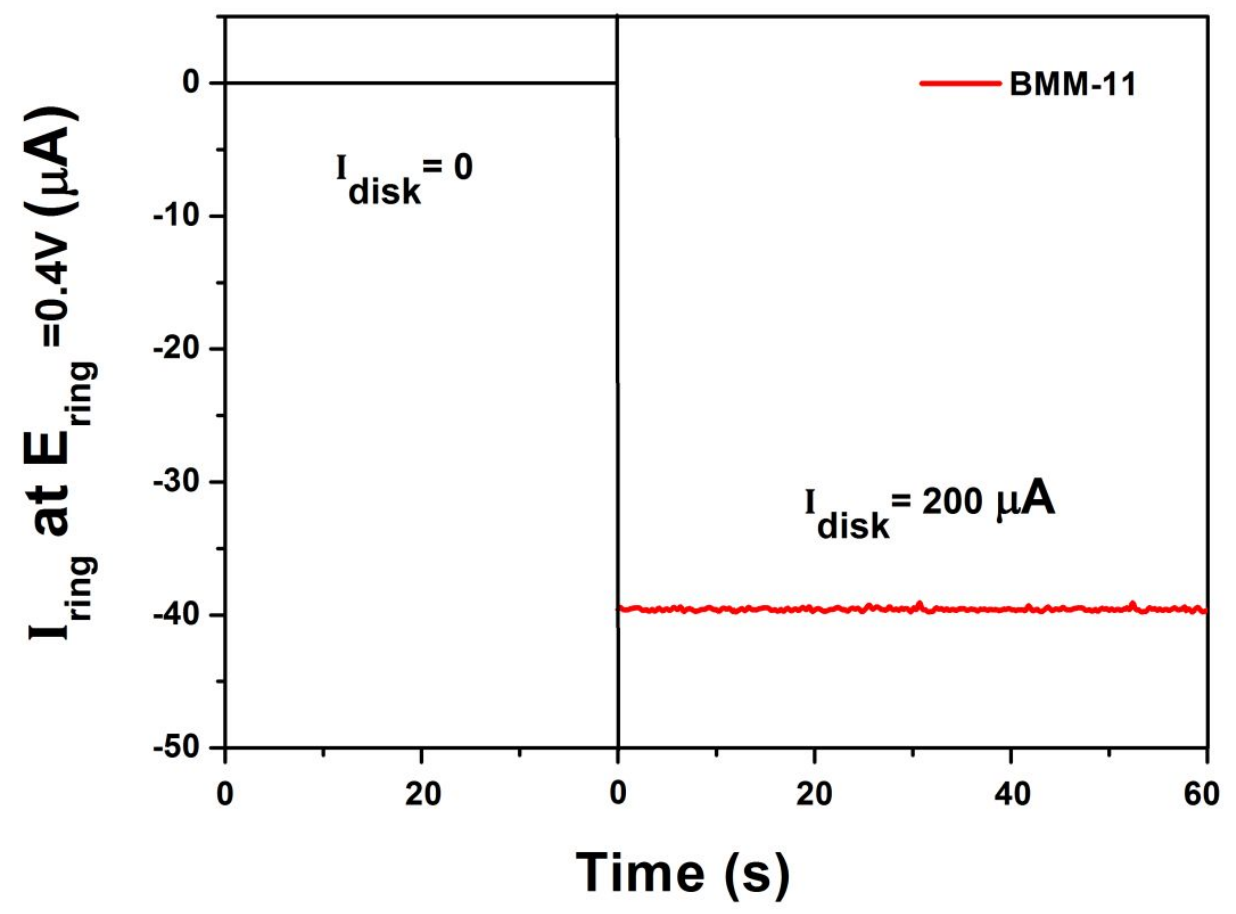

Figure S24. Ring current of BMM-11 on an RRDE in $\mathrm{N}_{2}$-saturated $1 \mathrm{M} \mathrm{KOH}$ electrolyte (ring potential $0.4 \mathrm{~V}$ ) and $\mathrm{I}_{\text {ring }}$ is collected about $38.6 \mu \mathrm{A}$ 
6. Performance comparison

\begin{tabular}{|c|c|c|c|}
\hline Catalyst & Elecrolyte & $\begin{array}{c}\boldsymbol{\eta}_{\mathbf{1 0}} \\
\left(\mathbf{m A} / \mathbf{c m}^{\mathbf{2}}\right)\end{array}$ & $\begin{array}{c}\text { Tafel slope } \\
\left(\mathbf{m V ~ d e c}^{-1}\right)\end{array}$ \\
\hline BMM-11 & $1 \mathrm{M} \mathrm{KOH}$ & 362 & 105.23 \\
\hline BMM-12 & $1 \mathrm{M} \mathrm{KOH}$ & 393 & 178.07 \\
\hline TS & $1 \mathrm{M} \mathrm{KOH}$ & 378 & 157.65 \\
\hline BMM-11-Ni & $1 \mathrm{M} \mathrm{KOH}$ & 348 & 158.32 \\
\hline BMM-12-Ni & $1 \mathrm{M} \mathrm{KOH}$ & 378 & 103.14 \\
\hline BMM-11-G & $1 \mathrm{M} \mathrm{KOH}$ & 339 & 96.12 \\
\hline BMM-12-G & $1 \mathrm{M} \mathrm{KOH}$ & 356 & 116.71 \\
\hline & $1 \mathrm{M} \mathrm{KOH}$ & 339 & \\
\hline
\end{tabular}

Table S7. Summarization of OER performance of our materials in this work.

\begin{tabular}{|c|c|c|c|c|}
\hline MOF Catalyst & Electrolyte & $\begin{array}{c}\eta_{10} \\
\left(\mathrm{~mA} / \mathrm{cm}^{2}\right)\end{array}$ & $\begin{array}{l}\text { Tafel slope } \\
\left(\mathrm{mV} \mathrm{dec}^{-1}\right)\end{array}$ & Reference \\
\hline BMM-11 & $1 \mathrm{M} \mathrm{KOH}$ & 362 & 105.23 & This work \\
\hline BMM-11-Ni & $1 \mathrm{M} \mathrm{KOH}$ & 348 & 81.17 & This work \\
\hline CoNi nanoflower & $1 \mathrm{M} \mathrm{KOH}$ & 356 & 62.6 & [6] \\
\hline $\mathrm{Co}-\mathrm{MOF}+\mathrm{SnO}_{2}$ & $1 \mathrm{M} \mathrm{KOH}$ & 388 & 68 & [7] \\
\hline $\mathrm{NGO} / \mathrm{Ni}_{7} \mathrm{~S}_{6}$ & $1 \mathrm{M} \mathrm{KOH}$ & 380 & n.a. & [8] \\
\hline
\end{tabular}




\begin{tabular}{|c|c|c|c|c|}
\hline Ni-MOF-74 & $1 \mathrm{M} \mathrm{KOH}$ & 640 & 108 & [9] \\
\hline $\begin{array}{c}\text { MOF-74 } \\
\text { (Cu-Ni-seed) }\end{array}$ & $1 \mathrm{M} \mathrm{KOH}$ & 624 & 108 & [9] \\
\hline 3D NiFe LDH & $0.1 \mathrm{M} \mathrm{KOH}$ & 460 & 65 & [10] \\
\hline MAX-X27-OH & $1 \mathrm{M} \mathrm{PB}$ & 489 & 127 & [11] \\
\hline MAX-X27-OH & $1 \mathrm{M} \mathrm{KOH}$ & 387 & 66 & [11] \\
\hline Co-BDC & $0.1 \mathrm{M} \mathrm{KOH}$ & 490 & 48.8 & [12] \\
\hline Co-WOC-1 & $0.1 \mathrm{M} \mathrm{KOH}$ & $390\left(1 \mathrm{~mA} / \mathrm{cm}^{2}\right)$ & 128 & [13] \\
\hline ZIF-67 & $0.1 \mathrm{M} \mathrm{KOH}$ & $443\left(4 \mathrm{~mA} / \mathrm{cm}^{2}\right)$ & n.a. & [13] \\
\hline ZIF-67/NPC-2(2:1) & $0.1 \mathrm{M} \mathrm{KOH}$ & 410 & 117 & [14] \\
\hline Co-MIL-101(Cr)-O & $0.1 \mathrm{M} \mathrm{KOH}$ & 477 & 122 & [15] \\
\hline Co-MIL-100(Fe) & $0.1 \mathrm{M} \mathrm{KOH}$ & $734\left(5 \mathrm{~mA} / \mathrm{cm}^{2}\right)$ & n.a. & [16] \\
\hline UIO-67 & $1 \mathrm{M} \mathrm{KNO}_{3}$ & 818 & n.a. & [17] \\
\hline
\end{tabular}

Table S8. Comparison of OER performance of BMM-11, BMM-11-Ni with other electrode materials. Blue noted means MOF directly as electrode materials. 


\section{Reference}

1. Azcarate, I; Costentin, C; Robert, M; Saveant, JM. Through-Space Charge Interaction Substituent Effects in Molecular Catalysis Leading to the Design of the Most Efficient Catalyst of $\mathrm{CO}_{2}$-to-CO Electrochemical Conversion. J. Am. Chem. Soc. 2016, 51, 16639-16644.

2. Zhang, RR; Zhang, YC; Pan, L; Shen, GQ; Mahmood, N; Ma, YH; Shi, Y; Jia, WY; Wang, L; Zhang, XW; Xu, W; Zou, JJ. Engineering Cobalt Defects in Cobalt Oxide for Highly Efficient Electrocatalytic Oxygen Evolution. ACS Catalysis. 2018, 8, 3803-3811.

3. Burke, MS; Kast, MG; Trotochaud, L; Smith, AM; Boettcher, SW. Cobalt-Iron (Oxy) hydroxide Oxygen Evolution Electrocatalysts: The Role of Structure and Composition on Activity, Stability, and Mechanism. J. Am. Chem. Soc. 2015, 10, 3638-3648.

4. Ma, TY; Dai, S; Jaroniec, M; Qiao, SZ. Metal-organic framework derived hybrid $\mathrm{Co}_{3} \mathrm{O}_{4}$-carbon porous nanowire arrays as reversible oxygen evolution electrodes. J. Am. Chem. Soc. 2014, 39, 13925-139331.

5. Duan, JJ; Chen, S; Zhao, C. Ultrathin metal-organic framework array for efficient electrocatalytic water splitting. Nat Commun. 2017, 15341.

6. Li, YW; Lu, MT; He, PP; Wu, YH; Wang, JW; Chen, DN; Xu, H; Gao, JK; Yao, JM. Bimetallic Metal-Organic Framework-Derived Nanosheet-Assembled Nanoflower Electrocatalysts for Efficient Oxygen Evolution Reaction. Chem Asian J. 2019, 14, 1590-1594.

7. Tian, JW; Wu, YP; Li, YS; Wei, JH; Yi, JW; Li, S; Zhao, J; Li, DS. Integration of Semiconductor Oxide and a Microporous $(3,10)$-Connected $\mathrm{Co}_{6}$-Based Metal-Organic Framework for Enhanced Oxygen Evolution Reaction. Inorg Chem. 2019, 9, 5837-5843.

8. Guo, YN; Park, T; Yi, JW; Henzie, J; Kim, J; Wang, ZL; Jiang, B; Bando, Y; Sugahara, Y; Tang, J; Yamauchi, Y. Nanoarchitectonics for Transition-Metal-Sulfide-Based Electrocatalysts for Water Splitting. Adv Mater. 2019. 17, 1807134.

9. Ma, XC; Qi, K; Wei, ST; Zhang, L; Cui, XQ. In situ encapsulated nickel-copper nanoparticles in metal-organic frameworks for oxygen evolution reaction. J. Alloys. Compd. 2019, 770, 236-242.

10. Zhao, ZL; Wu, HX; He, HL; Xu, XL; Jin, YD. A High-Performance Binary Ni-Co Hydroxide-based Water Oxidation Electrode with Three-Dimensional Coaxial Nanotube Array Structure. Adv. Funct. Mater. 2014, 24, 4698-4705.

11. Lu, XF; Liao, PQ; Wang, JW; Wu, JX; Chen, XW; He, CT; Zhang, JP; Li, GR; Chen, XM. An Alkaline-Stable, Metal Hydroxide Mimicking Metal-OrganicFramework for Efficient Electrocatalytic Oxygen Evolution. J. Am. Chem. Soc. 2016, 27, 8336-8339.

12. Zhao, L; Dong, BL; Li, SZ; Zhou, LJ; Lai, LF; Wang, ZW; Zhao, SL; Han, M; Gao, K; Lu, M; Xie, XJ; Chen, B; Liu, ZD; Wang, XJ; Zhang, H; Li, H; Liu, JQ; Zhang, H; Huang, X; Huang, W. Interdiffusion Reaction-Assisted Hybridization of Two-Dimensional Metal-Organic Frameworks and $\mathrm{Ti}_{3} \mathrm{C}_{2} \mathrm{~T}_{\mathrm{x}}$ Nanosheets for Electrocatalytic Oxygen Evolution. ACS Nano. 2017, 11, 5800-5807.

13. Kottur, J; Debgupta, J; Bose, S; Das, SK; Manna, P. A Mononuclear Co-II Coordination Complex Locked in a Confined Space and Acting as an Electrochemical Water-Oxidation Catalyst: A "Ship-in-a-Bottle" Approach. Angew.Chem. 2016, 55, 2425-2430. 
14. Wang, H; Yin, FX; Chen, BH; He, XB; Lv, PL; Ye, CY; Liu, DJ Wang, H. ZIF-67 incorporated with carbon derived from pomelo peels: A highly efficient bifunctional catalyst for oxygen reduction/evolution reactions. Appl. Catal., B-Environ. 2017, 205, 55-67.

15. He, XB; Yin, FX; Li, GR. A Co/metal-organic-framework bifunctional electrocatalyst: The effect of the surface cobalt oxidation state on oxygen evolution/reduction reactions in an alkaline electrolyte. Int. J. Hydrogen Energy. 2015, 31, 9713-9722.

16. Wang, H; Yin, FX; Li, GR; Chen, BH; Wang, ZQ. Preparation, characterization and bifunctional catalytic properties of $\mathrm{MOF}(\mathrm{Fe} / \mathrm{Co})$ catalyst for oxygen reduction/evolution reactions in alkaline electrolyte. Int. J. Hydrogen Energy. 2014, 39, 16179-16186.

17. Johnson, BA; Bhunia, A; Ott, St. Electrocatalytic water oxidation by a molecular catalyst incorporated into a metal-organic framework thin film. Dalton Trans. 2017, 5, 1382-1388. 